\section{Band 40,}

Supplement 1, März 2017

Online only

\section{ASORS-Jahreskongress}

Supportive Therapie und

Rehabilitation bei Krebs -

State of the Art 2017

München, 31. März -1. April 2017

\title{
ABSTRACTS
}

Herausgeber

Petra Feyer, Berlin

Oliver Rick, Bad Wildungen

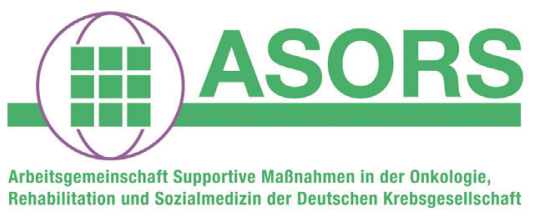




\section{SB $=$ Sport/Bewegung}

SU = Supportivtherapie

$\mathbf{R E}=$ Rehabilitation

TP $=$ Trials in Progress

Ausgezeichnet als einer von 6 Best Abstracts

\section{Interessenkonflikte}

Die Herausgeber erklären, dass keine Interessenkonflikte bestehen.

\section{Imprint}

ISSN Print Edition: 2296-5270

ISSN Online Edition: 2296-5262

Journal Homepage: http://www.karger.com/ort

Publication Data: Volume 40, 2017 of 'Oncology Research and Treatment' appears with 12 issues.

Copyright: ๑ 2017 by S. Karger Verlag für Medizin und Naturwissenschaften GmbH, Freiburg (Germany). All rights reserved. No part of this publication may be translated into other languages, reproduced or utilized in any form or by any means, electronic or mechanical, including photocopying, recording, microcopying, or by any information storage and retrieval system, without permission in writing from the publisher.

Disclaimer: The statements, opinions and data contained in this publication are solely those of the individual authors and contributors and not of the publisher and the editor(s). The appearance of advertisements in the journal is not a warranty, endorsement, or approval of the products or services advertised or of their effectiveness, quality or safety. The publisher and the editor(s) disclaim responsibility for any injury to persons or property resulting form any ideas, methods, instructions or products referred to in the content or advertisements.

Subscription Rates: Subscriptions run for a full calendar year.

Prices are given per year.

Print:

EUR 269.00 + postage and handling

Online:

EUR 269.00

Combined (print+online): $\quad$ EUR $319.00+$ postage and handling

Postage and handling (added to print and print+online):

EUR 30.00 (Germany), EUR 40.00 (Rest of World)

Discount subscription prices:

Please enquire about reduced rates for members of related societies.

Back Volumes and Single Issues: Information on availability and prices of single print issues and print or electronic back volumes can be obtained from Customer Service at aboservice@karger.com
For customers in Germany: Please contact your local bookstore or

$\mathrm{S}$. Karger Verlag für Medizin und Naturwissenschaften $\mathrm{GmbH}$

Wilhelmstr. 20A, 79098 Freiburg (Germany)

Tel. +49761 452070 , Fax +497614520714

aboservice@karger.com

For customers in all other countries: Please contact your bookshop or

S. Karger AG

Allschwilerstr. 10, 4009 Basel (Switzerland)

Tel. +4161306 11 11, Fax +41613061234

karger@karger.com

Advertising: Correspondence should be addressed to the publisher.

S. Karger Verlag für Medizin und Naturwissenschaften GmbH

Attn. Ellen Zimmermann (Head of Marketing)

e.zimmermann@karger.com

Price list No. 27 of January 1, 2017 is effective.

Publisher: S. Karger Verlag für Medizin und Naturwissenschaften GmbH

Wilhelmstr. 20A, 79098 Freiburg (Germany)

www.karger.de, information@karger.com

V.i.S.d.P. (Person responsible according to the German Press Law):

Sibylle Gross

\section{Indexing/Abstracting}

Listed in bibliographic services, including:

PubMed / MEDLINE / Web of Science / Science Citation Index / Science Citation Index Expanded / Current Contents - Clinical Medicine / BIOSIS Previews / Google Scholar /

Chemical Abstracts Service / Scopus / Embase / Pathway Studio / WorldCat

Supplement $1 / 2017$

e-ISBN 978-3-318-06066-9

\section{KARGER}




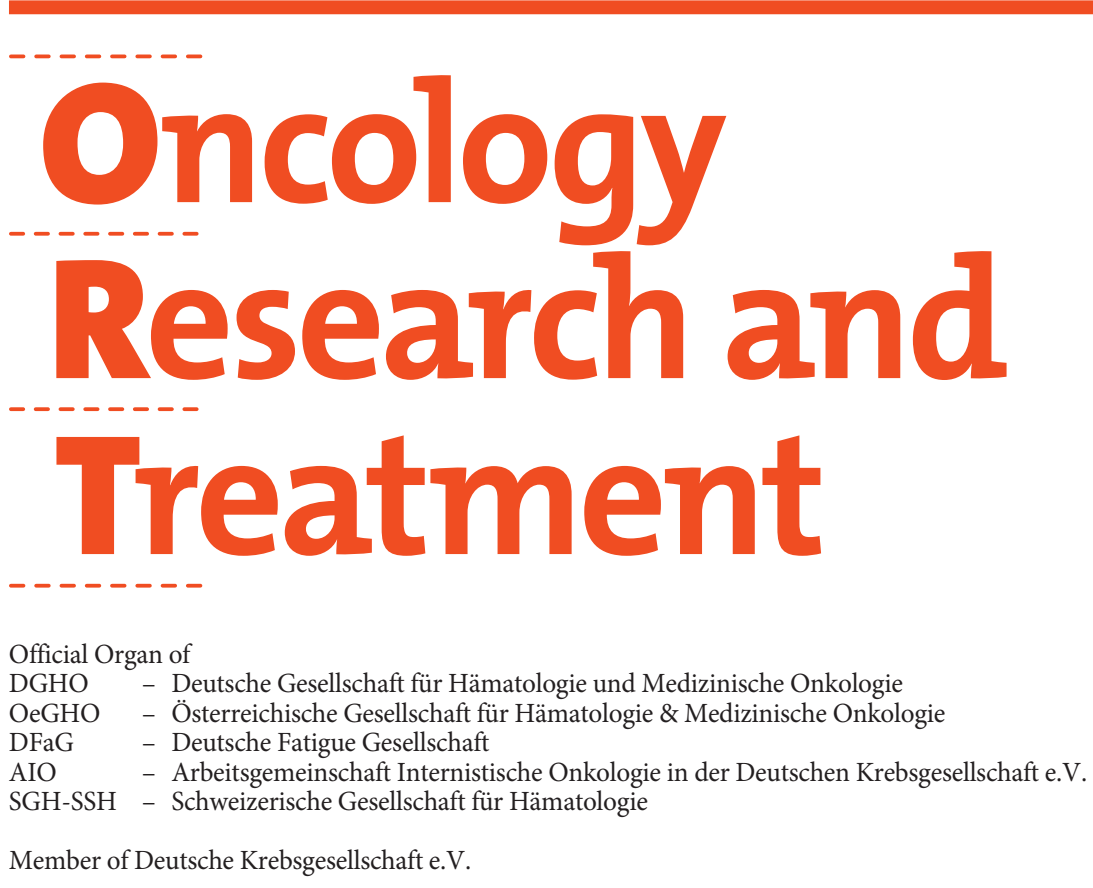

Editors

Editor-in-Chief

M. Hallek, Cologne

\section{Associate Editors}

S. Al-Batran, Frankfurt/M.
C. Berking, Munich
C. Bokemeyer, Hamburg
M. Borner, Bern
T. Cerny, St. Gallen
C. Dierks, Freiburg i.Br.
H. T. Eich, Münster
A. Engert, Cologne
F. Geiser, Bonn
A. Heidenreich, Cologne
M. Hentrich, Munich
R.-D. Hofheinz, Mannheim
W. Janni, Ulm
K. Jordan, Heidelberg

J. P. Klussmann, Gießen

M. Kroiss, Würzburg

A. A. Lammertsma, Amsterdam

H. Lang, Mainz

M. Moehler, Mainz

K. Oechsle, Hamburg

C. P. Pallasch, Cologne

P. Reichardt, Berlin

M. Schuler, Essen

J. Sehouli, Berlin

R. Stupp, Zürich

M. Theobald, Mainz

U. Wedding, Jena

\section{Editorial Board}

P. Albers, Düsseldorf

D. Arnold, Lisbon

C. Bausewein, Munich

L. Bergmann, Frankfurt/M.

D. Beutner, Cologne

J. Boos, Münster

P. Brossart, Bonn

W. Budach, Düsseldorf

R. Büttner, Bonn

J. Debus, Heidelberg

E. Dippel, Ludwigshafen

M. Fassnacht, Würzburg
T. Fehm, Düsseldorf

N. Harbeck, Munich

U. Herrlinger, Bonn

A. Hochhaus, Jena

F. Honecker, St. Gallen

R. D. Issels, Munich

U. R. Kleeberg, Hamburg

H. Kölbl, Vienna

W. Kuhn, Bonn

T. Langer, Lübeck

H.-J. Lenz, Los Angeles

P. Mallmann, Cologne
D. Marmé, Freiburg i.Br.

H. Moch, Zürich

I. Runnebaum, Jena

P. Schöffski, Leuven

C. Spitzweg, Munich

I. Strohscheer, St. Peter-Ording

S. Ugurel, Essen

R. Voltz, Cologne

M. Weller, Zürich

T. Zander, Cologne

O. Zivanovic, New York

\section{Editorial Office}

S. Karger GmbH

Attn. Dr. Steffi Hentzelt

P.O. Box

D-79095 Freiburg

E-mail s.hentzelt@karger.com 


\section{Oncology Research and Treatment}

Abstracts

Oncol Res Treat 2017;40(suppl 1):1-19

DOI: $10.1159 / 000464477$
SB1

Effekte von körperlichem Training während der Strahlentherapie auf Schlafprobleme: Eine randomisierte, klinische Studie mit Brustkrebspatientinnen

\section{Steindorf, K. ${ }^{1}$; Wiskemann, J. ${ }^{2}$; Ulrich, C.M. ${ }^{3}$; Schmidt, M.E. ${ }^{1}$}

${ }^{1}$ Abteilung Bewegung, Präventionsforschung und Krebs, Deutsches Krebsforschungszentrum (DKFZ) und Nationales Centrum für Tumorerkrankungen (NCT), Heidelberg

${ }^{2}$ Abteilung Medizinische Onkologie, Universitätsklinikum Heidelberg und Nationales Centrum für Tumorerkrankungen (NCT), Heidelberg,

${ }^{3}$ Department of Population Health Sciences, Huntsman Cancer Institute and University of Utah, Salt Lake City, USA

Hintergrund: Brustkrebspatientinnen leiden häufig sowohl während als auch nach der Krebsbehandlung unter Schlafproblemen. Ihre Lebensqualität wird dadurch erheblich beeinträchtigt. Zudem wurden Assoziationen von Schlafproblemen mit Fatigue, Ängstlichkeit, Depressivität und eingeschränkter sozialer Funktionsfähigkeit berichtet. Wirksame Behandlungsstrategien sind kaum bekannt [1]. Allerdings gibt es Hinweise, dass körperliches Training Schlafprobleme reduzieren kann. Für Brustkrebspatientinnen während der Strahlentherapie liegen bislang nur dre randomisierte Sporttrainingsstudien vor, die alle weniger als 50 Teilnehmerinnen umfassten.

Methode: In einer randomisierten, klinischen Studie (ClinicalTrials.gov NCT01468766) untersuchten wir die Effekte eines 12-wöchigen supervidierten, progressiven Krafttrainings auf die Schlafqualität bei Brustkrebspatientinnen unter Strahlentherapie im Vergleich zu einem Entspannungstraining. 160 Brustkrebs-patientinnen (Stadien 0-III) wurden vor Beginn der adjuvanten Strahlentherapie randomisiert dem Kraft- oder dem Entspannungstraining zugewiesen $(2 \times 1$ Std./Woche). Die allgemeine Schlafqualität (4 Punkte Likert Skala) sowie verschiedene Schlafcharakteristika wurden mittels Selbstbericht vor Beginn der Intervention und der Strahlentherapie, nach 6 Wochen (Ende der Strahlentherapie), nach 12 Wochen (Ende der Interventionsphase) sowie 2, 6 und 12 Monate nach der Intervention erfasst. Als zusätzliche Vergleichsgruppe durchliefen 25 gesunde Frauen gleichen Alters analog das Krafttrainingsprogramm sowie das sonstige Studienprotokoll. Die sekundären Auswertungen erfolgten mittels ordinaler logistischer Regression nach dem Intent-to-treat Prinzip. Ergebnisse: In der randomisierten Studie zeigten sich statistisch signifikante Gruppenunterschiede zugunsten des Krafttrainings hinsichtlich des allgemeinen Auftretens von Schlafproblemen. Während die Schlafprobleme in den ersten 12 Wochen nach Beginn der Strahlentherapie in der Entspannungsgruppe anstiegen, nahmen sie in der Krafttrainingsgruppe ab. Basierend auf einer Skalierung von 0-100 unterschieden sich die Interventionsgruppen im Mittel um -10.2 ( $p=0.03)$ bezüglich der Differenzen von Baseline zum Ende der Strahlentherapie sowie um -10.9 $(p=0.005)$ bezüglich der mittleren Differenzen von Baseline zum Ende der Intervention. Nach 12 Monaten bestanden weiterhin Unterschiede, sie waren jedoch nicht mehr statistisch signifikant (mittlere Differenz $=-5.9$, $p=0.20$ ). Weitere Adjustierungen für potenzielle Confounder veränderten die Ergebnisse nicht. Der Verlauf der Schlafprobleme bei gesunden Frauen verlief parallel zu dem der trainierenden Patientinnengruppe, allerdings beginnend auf einem deutlich niedrigeren Niveau. Darüber hinaus wurden verschiedene Determinanten für Schlafprobleme an Baseline identifiziert. So wiesen Patientinnen mehr Schlafprobleme auf, wenn der
Strahlentherapie eine Chemotherapie vorausgegangen war oder wenn sie einen höheren Body Mass Index hatten. Die positiven Effekte von körperlichem Training für die Verringerung von Schlaf-problemen generell konnten nicht durch Effekte auf spezifische Schlafcharakteristika erklärt werden.

Schlussfolgerung: In dieser randomisierten Interventionsstudie zu körperlichem Training bei Brustkrebspatientinnen unter Strahlentherapie stellte Krafttraining eine wirksame Strategie zur Reduzierung von Schlafproblemen dar. Damit wurden Ergebnisse früherer, meist aber kleiner Studien bestätigt. Die beobachteten Effekt-stärken können als medizinisch relevant eingestuft werden [2]. Schlafprobleme zu behandeln gilt als einer der schnellsten und effektivsten Wege, die Lebensqualität und die Gesundheit von Brustkrebspatientinnen zu verbessern [3]. Insgesamt sind unsere Ergebnisse somit von großer Bedeutung für viele Brustkrebspatientinnen und ihre medizinische und sporttherapeutische Versorgung.

\section{Literatur}

1. Savard J, Villa J, Ivers H, Simard S, Morin CM: Prevalence, natural course, and risk factors of insomnia comorbid with cancer over a 2-month period. Journal of Clinical Oncology 27 (31);2009:5233-5239. doi:10.1200/JCO.2008.21.6333.

2. Cocks K, King MT, Velikova G, de Castro G, Jr., Martyn St-James M, Fayers PM, Brown JM: Evidence-based guidelines for interpreting change scores for the European Organisation for the Research and Treatment of Cancer Quality of Life Questionnaire Core 30. European Journal of Cancer 48 (11);2012:17131721. doi:10.1016/j.ejca.2012.02.059.

3. Jain S, Boyd C, Fiorentino L, Khorsan R, Crawford C: Are there efficacious treatments for treating the fatigue-sleep disturbance-depression symptom cluster in breast cancer patients? A Rapid Evidence Assessment of the Literature. Breast Cancer 7;2015:267-291. doi:10.2147/BCTT.S25014.

Interessenkonflikte: Keiner der Autoren hat einen Interessenskonflikt.

\section{SB2}

\section{SENSe-Studie (Strukturierte Evaluation von Sport nach Krebs):} Eine randomisiert kontrollierte Studie

Roggenhofer, S. ${ }^{1}$; Schneider, A. ${ }^{2}$; Rössler, R. ${ }^{3}$; Widmann, T. $^{2,4}$

${ }^{1}$ Waldklinik Dobel, Dobel,

${ }^{2}$ Asklepiosklinik Triberg, Triberg,

${ }^{3}$ Departement für Sport, Bewegung und Gesundheit der Universität Basel, Basel Schweiz,

${ }^{4}$ Medizinische Fakultät der Universität des Saarlandes Campus Homburg/Saar (T.Widmann@asklepios.com)

Hintergrund: Tumorpatienten, welche sich nach einer Tumorerkrankung einem regelmäßigen Bewegungsprogramm anschließen, haben Aussicht auf eine Absenkung des Rückfallrisikos und damit eine verbesserte Überlebenswahrscheinlichkeit. Die Absenkung des Rückfallrisikos hängt davon ab, wie hoch die «Dosis» der Bewegung ist. Verschiedene Bewegungsaktivitäten werden durch einen unterschiedlichen Kalorienverbrauch bzw. durch die Angabe von sogenannten metabolischen Äquivalenzeinheiten $(=\mathrm{MET})$ erfasst und bewertet. Die hier präsentierte Studie adressiert die Fragen, ob 1. das Setting einer medizinischen Rehabilitation dafür geeignet ist, Tumorpatienten auf ein prognostisch relevantes Bewegungsniveau zu bringen und 2. eine strukturierte Trainingsempfehlung dabei helfen kann, die körperliche Aktivität von Patienten nachhaltig und in relevantem Umfang zu erhöhen. 
Methode: Wir untersuchten $n=340$ Rehabilitanden in einer prospektiven, randomisierten und einfach verblindeten Single-Center Studie. Alle Rehabilitanden, die eine medizinische Rehabilitation antraten, konnten an der Studie teilnehmen. Ausschlusskriterien umfassten lediglich eine akut behandlungspflichtige Erkrankung. Die Studie wurde durch die Ethikkommission Baden-Württemberg begutachtet und genehmigt. Alle Rehabilitanden wurden hinsichtlich des Niveaus der Bewegungsaktivität vor der Rehabilitationsmaßnahme befragt (GermanPAQ50+). Basierend auf wesentlichen epidemiologischen Studien wurde ein prognostisch relevantes Bewegungsniveau von 27 MET-h pro Woche festgelegt. Während der medizinischen Rehabilitation absolvierten die Rehabilitanden ein Bewegungsprogramm entsprechend der Leitlinien der Deutschen Rentenversicherung und führten zusätzlich ein Bewegungstagebuch (Erfassung von Bewegungsaktivitäten die außerhalb des Therapieplans selbstständig durchgeführt wurden). Zum Ende der Reha erfolgte eine für den Arzt verblindete 1:1 Randomisierung der Rehabilitanden in eine Experimentalgruppe $(\mathrm{n}=170$ Patienten); mit unterstützender und strukturierter Trainingsempfehlung und eine Kontrollgruppe ( $\mathrm{n}=170$ Patienten) ohne Trainingsempfehlung sondern mit der alleinigen Empfehlung der Fortführung des in der medizinischen Rehabilitation erlernten Bewegungsprogramms. Nach drei und sechs Monaten erfolgte eine Nachbefragung der Patienten zu ihrer selbstständig durchgeführten Bewegungsaktivität. Zusätzlich erfolgte in einem Teil der Kohorte $(n=7)$ über einen Zeitraum von 7 Tagen die Aufzeichnung der Bewegungsaktivitäten während der medizinischen Rehabilitation sowie im ambulanten Setting mittels sogenannter «Bewegungstracker» (SenseWear-Armband).

Ergebnisse: Die eingeschlossenen Rehabilitanden erreichten vor der medizinischen Rehabilitation ein durchschnittliches Bewegungsniveau von 22,5 MET-h/Woche ( $S D=25,7)$. Während der medizinischen Rehabilitation konnte das Bewegungsniveau auf durchschnittlich 38,5 MET-h/Woche $(\mathrm{SD}=15,9 ; \mathrm{p}<0,001)$ gesteigert werden. 3 Monate nach der medizinischen Rehabilitation lag das Bewegungsniveau bei durchschnittlich 41,1 MET-h/Woche und nach 6 Monaten bei 43,4 MET-h/Woche $(\mathrm{p}<0,001)$. Eine Post-hoc Analyse zeigte ein nach 3 Monaten deutlich höheres Bewegungsniveau der Experimental- im Vergleich zur Kontrollgruppe. Nach 3 Monaten erreichte die Experimentalgruppe durchschnittlich 55,7 MET-h/Woche $(\mathrm{SD}=37,0)$ und die Kontrollgruppe 36,3 MET-h/Woche $(\mathrm{SD}=28,4 ; \mathrm{p}<0,001)$. Es zeigte sich eine hohe Korrelation der von Patienten schriftlich dokumentierten Bewegungsaktivitäten mit den Ergebnissen der Aufzeichnungen mittels Bewegungstracker $(\mathrm{R}=0,88 ; \mathrm{p}=0,012)$. Schlussfolgerung: Viele Tumorpatienten führen bereits vor der medizinischen Rehabilitation ein Bewegungsprogramm durch. Das Setting der medizinischen Rehabilitation ist hinsichtlich Edukation und Anleitung zur regelmäßigen Bewegung besonders geeignet und führt zu einer prognostisch relevanten Steigerung des Bewegungsniveaus.

Über den Zeitraum der medizinischen Rehabilitation hinaus kann eine strukturierte Anleitung (im Sinne eines Trainingsplans) die konsequente Fortsetzung eines Bewegungsprogramms maßgeblich verbessern. Dadurch besteht Aussicht auf eine relevante Absenkung des Rückfallrisikos, wodurch die Wahrscheinlichkeit steigt, die Krebserkrankung zu überleben.

Interessenkonflikte: Simone Roggenhofer: keine; Andre Schneider: keine; Roland Rössler: keine; Thomas Widmann: keine.
SB3

\section{Einfluss der Konditionierung und Glukokortikoidtherapie} auf Trainingsadhärenz und -response bei allogener Stammzelltransplantation

Kühl, R. ${ }^{1}$; Herzog, B. ${ }^{\text {; }}$ SSchmidt, M.E. ${ }^{2}$; Dreger, P. ${ }^{3}$; Bohus, M. $^{4}$; Wiskemann, J.'

${ }^{1}$ AG Onkologische Sport- und Bewegungstherapie, Medizinische Onkologie, Nationales Centrum für Tumorerkrankungen (NCT), Heidelberg,

${ }^{2}$ Abteilung Bewegung, Präventionsforschung und Krebs, Deutsches Krebsforschungszentrum (DKFZ), Heidelberg,

${ }^{3}$ Abteilung Innere Medizin V, Universitätsklinikum Heidelberg,

${ }^{4}$ Klinik für Psychosomatik und Psychotherapeutische Medizin, Zentralinstitut für Seelische Gesundheit, Mannheim

Hintergrund: Eine allogene Stammzelltransplantation (allo-HCT) stellt für Patienten mit hämatologischen Erkrankungen oftmals die einzige mögliche Therapieoption mit kurativer Absicht da. Die intensive Therapie ist mit einer Vielzahl von therapiebedingten Nebenwirkungen und Komplikationen assoziiert, welche sich auf physischer und psycho-sozialer Ebenen manifestieren und zu einer massiven Einschränkung der Lebensqualität führen. Erste randomisierte Studien (RCTs) zeigen eindrücklich, in wie weit körperliche Trainingsprogramme zu einer Reduktion dieser Nebenwirkungen beitragen $[1,2]$. Therapieassoziierte Einflüsse können die Rehabilitation der Patienten jedoch negativ beeinflussen. Zu nennen wären hier u.a. die Intensität der Konditionierung vor allo-HCT und die Gabe von Glukokortikoiden. Das Ziel dieser Untersuchung war es daher, die Trainingsadhärenz und Trainingsresponse in Abhängigkeit von der Intensität der Konditionierung und Gabe von Glukokortikoiden darzustellen. Das Wissen um mögliche klinische Einflussparameter auf die Trainingsadhärenz und Trainingsresponse ist notwendig für zukünftige Interventionsgestaltungen.

Methoden: Die analysierten Daten stammen aus zwei randomisierten, kontrollierten Trainingsinterventionsstudie mit Patienten unter allo-HCT $[2,3]$. Es wurden insgesamt $n=113$ Experimentalgruppen-Patienten zum Zeitpunkt der stationären Aufnahme zur allo-HCT eingeschlossen. Die Intervention bestand aus einem teilweise supervidiertem Kraft- und Ausdauertraining, welches $5 \times /$ Woche auf der Isolierstation durchgeführt wurde. Die Patienten wurden einmal klassifiziert nach Intensität der Konditionierung (myeloablativ (MAC), reduzierte Intensität (RIC) und nichtmyeloablativ (NMC)); und einmal nach der kumulativen Dosis der verabreichten Glukokorticoide (cut-off $\leq 9 \mathrm{mg} / \mathrm{kg}$ Prednison). Die Gruppen wurden hinsichtlich Adhärenz und Response verglichen.

Ergebnisse: Die Patienten wiesen einen Altersschnitt von $51 \pm 13$ Jahren auf, $64 \%$ der Patienten waren männlich. Die Trainingsadhärenz betrug 64\% (71 min/Woche) in der MAC Gruppe, 54\% (84 min/Woche) in der RIC Gruppe und 63\% (100min/Woche) in der NMC Gruppe, war jedoch nicht signifikant beeinflusst durch die Intensität der Konditionierung. In Bezug auf die Trainingsresponse gab es ebenfalls keinen signifikanten Einfluss durch die Intensität der Konditionierung. Hinsichtlich der Glukokortikoide zeigte sich, dass die Trainingsdauer pro Woche in der Gruppe der Patienten mit weniger als 9mg/kg Prednison (GC Low, 92min/Woche) signifikant höher war als bei den Patienten, die mehr Kortikoide erhalten haben (GC High, 71min/Woche). Zusätzlich führte die GC Low Gruppe signifikant mehr Krafttrainingseinheiten durch. Auch hinsichtlich der Trainingsresponse zeigte sich, dass die GC Low Gruppe insgesamt weniger Kraftverlust der Kniestrecker aufwies als die GC High Gruppe. Dieser Unterschied wurde allerdings nicht signifikant.

Schlussfolgerung: Die Trainingsadhärenz kann insgesamt als gut bezeichnet werden. Je intensiver die Konditionierung, desto kürzer war die wöchentliche Trainingsdauer. Diese Beobachtung lässt sich vermutlich auf vermehrte Nebenwirkungen der intensivieren Konditionierung zurückführen und wird unterstrichen durch die Beobachtung, dass die MAC Gruppe die höchste Anzahl an abgebrochenen Trainingseinheiten hatte. Obwohl die GC Low Gruppe signifikant länger und öfter trainierte als die GC High Gruppe, gab es keine signifikanten Unterschiede in der Trainingsresponse. Eine mögliche Erklärung ist, dass die Intensität des Trainingsprogramms nicht ausreichend war um eine positivere Trainingsadaptation zu erreichen. Da wir keinen signifikanten Unterschied zwi- 
schen der GC Low und GC High Gruppe bezüglich der Trainingsresponse feststellen konnten lässt sich mutmaßen, dass der katabole Effekt von Glukokortikoiden auf die Skelettmuskulatur durch das Training abgemildert wurde. Insgesamt lässt sich schlussfolgern, dass der zu erwartende Verlust der körperlichen Leistungsfähigkeit nicht durch die Intensität der Konditionierung oder die Dosis der Glukokortikoide erklärbar ist.

\section{Interessenkonflikte: keine.}

\section{Literatur}

1. Persoon S, Kersten MJ, van der Weiden K, Buffart LM, Nollet F, Brug J et al.: Effects of exercise in patients treated with stem cell transplantation for a hematologic malignancy: a systematic review and meta-analysis. Cancer Treat Rev 2013;39:682-690.

2. Wiskemann J, Dreger P, Schwerdtfeger R, Bondong A, Huber G, Kleindienst N et al.: Effects of a partly self-administered exercise program before, during, and after allogeneic stem cell transplantation. Blood 2011;117:2604-2613.

3. Wiskemann J, Kuehl R, Dreger P, Huber G, Kleindienst N, Ulrich CM, Bohus M (2015): Physical Exercise Training versus Relaxation in Allogeneic stem cell transplantation (PETRA Study) - Rationale and design of a randomized trial to evaluate a yearlong exercise intervention on overall survival and side-effects after allogeneic stem cell transplantation. BMC Cancer 15(1):619.

\section{SB4}

\section{Evaluation einer dezentralen Bewegungsintervention mit Aktivitätstrackern während der onkologischen Therapie bei Kindern und Jugendlichen}

\section{Götte, M. ${ }^{1}$; Kesting, S. ${ }^{1}$; Rosenbaum, D. ${ }^{2}$; Boos, J. ${ }^{1}$}

${ }^{1}$ Pädiatrische Hämatologie und Onkologie, Klinik für Kinder- und Jugendmedizin, Universitätsklinikum Münster,

${ }^{2}$ Funktionsbereich Bewegungsanalytik, Institut für Experimentelle Muskuloskelettale Medizin, Universitätsklinikum Münster

Hintergrund: Erste Studien belegen, dass Kinder und Jugendliche während einer onkologischen Therapie auf psychischer und physischer Ebene von stationärer und ambulanter Bewegungstherapie profitieren. Während der regelmäßigen Aufenthalte zu Hause ist eine persönliche Betreuung jedoch aufgrund der großen Einzugsgebiete häufig nicht umsetzbar. Diese Studie evaluiert eine Bewegungsintervention, die auf individuell gestalteten Übungsplänen sowie Zielvorgaben für tägliche Schritte und aktive Minuten basiert. Als primäres Studienziel wurde die Verbesserung der Umsetzungsraten der Zielvorgaben im intra-individuellen Verlauf definiert. Sekundäre Studienziele waren die Erfassung der Effekte auf die gesundheitsbezogene Lebensqualität, die sportmotorische Leistungsfähigkeit sowie die Erhebung der Einstellungen und Zufriedenheit mit der Intervention.

Methode: Das Kollektiv dieser prospektiven, nicht randomisierten, kontrollierten Studie umfasst insgesamt 40 Patienten $(14,7 \pm 3.9$ Jahre alt, $35 \%$ Leukämie, 28\% Lymphome, 25\% Knochentumore, 13\% andere). Für die Interventionsgruppe (IG) wurde während der Akuttherapie ein individueller Bewegungsplan für die Heimaufenthalte ausgearbeitet, basierend auf einer Ist-Analyse (T1: objektive Erfassung des Aktivitätsniveaus $\left(\right.$ Fitbit $\left.^{\circledR}\right)$, sportmotorische Leistungsfähigkeit (MOON), Sportanamnese (Aktivitätsfragebogen), gesundheitsbezogene Lebensqualität (KINDL) und sportbezogene Motivation (Fragebogen)). Der Bewegungsplan beinhaltet neben einer Zielvorgabe für die Anzahl der täglichen Schritte und aktiven Minuten individuell angepasste Übungen zur Kräftigung, Koordination und gegebenenfalls Ausdauer. Die Intervention wird über einen Zeitraum von sechs bis acht Wochen durchgeführt. Innerhalb von drei Monaten nach Abschluss der Akuttherapie erfolgt eine zweite zweiwöchige IST-Analyse (T2), wie zu Beginn der Intervention. Primärer Endpunkt der Studie ist die Umsetzungsrate definierter, individueller Aktivitätsziele mit einer maximalen Abweichung von $< \pm 30 \%$ in der Interventionsgruppe. Zusätzlich werden die Umsetzungsraten, die sportmotorische Leistungsfähigkeit und die gesundheitsbezogene Lebensqualität zu T2 mit einer Kontrollgruppe (KG) verglichen, die während der Akuttherapie keine Intervention erhalten hat. Als Biofeedback und zur dezentralen Kontrolle durch den Studienleiter erhält jeder Teilnehmer einen Aktivitätstracker $\left(\right.$ Fitbit $\left.^{\circledR}\right)$. Die Zufriedenheit und Einstellungen wurden durch Leitfadeninterviews erfasst.

Ergebnisse: Das Interventionsprogramm ließ sich bei $96 \%$ der angesprochenen Patienten problemlos etablieren. Die Compliance mit den Zielvorgaben (Umsetzungsraten) zu beiden Messzeitpunkten verbesserte sich innerhalb der Interventionsgruppe signifikant für Schritte (T1: 38,5\%, T2: $51,7 \%, p=0.04$ ), aber nur leicht für aktive Minuten (T1: $9.5 \%$, T2: $15.8 \%, \mathrm{p}=0.23$ ). Zu T2 waren im Gruppenvergleich (IG vs. KG) keine signifikante Unterschiede in den Umsetzungsraten nachweisbar. Die IG schätze jedoch ihr LQ höher ein (Gesamtskala und Unterskalen körperliches Wohlbefinden und Selbstwert (jeweils $\mathrm{p}<0,001$ ). Die sportmotorische Leistungsfähigkeit unterschied sich nicht signifikant voneinander, jedoch erzielten prozentual mehr Teilnehmer der KG bessere Werte in allen Krafttests (Handkraft, Beinkraft, Schnellkraft). 94\% aller Studienteilnehmer bewertete die Intervention als sinnvoll und $80 \%$ als motivierend um körperliche Aktivitäten auszuüben während 23\% abnehmende motivationale Effekte mit zunehmender Dauer der Studie angaben.

Schlussfolgerung: Insgesamt war die Intervention sicher und wurde von den Patienten gut akzeptiert. Umsetzungsraten von Schrittzielen scheinen durch die Intervention trainierbar zu sein. Die Interventionsgruppe schätzte ihre Lebensqualität am Therapieende wesentlich höher ein als die Kontrollgruppe; insbesondere das Selbstwertgefühl. Dieser Effekt könnte auf das Interventionskonzept zurückzuführen sein, dessen Schwerpunkt auf dem Erreichen von Zielen und eigenständig durchgeführten Übungen liegt. Im Gegensatz dazu scheinen die Übungen keinen großen Effekt auf die sportmotorische Leistungsfähigkeit zu haben. Dies könnte auf fehlende Einhaltung der Trainingseinheiten oder zu niedrige Trainingsintensitäten im Eigentraining zurückzuführen sein. Da die Zielvorgaben sowohl über- als auch unterschritten wurden und der regelmäßige Kontakt zum Studienleiter unverzichtbar für die Compliance war, können wir dieses Programm zukünftig für Kinder während und nach der Therapie empfehlen, betonen aber die Notwendigkeit einer regelmäßigen Supervision und Rücksprache mit den Patienten.

Interessenkonflikte: Es liegen keine Interessenskonflikte vor.

\section{SB5 \\ Zielgruppenorientierte sport- und bewegungstherapeutische Angebote für onkologische Patienten: Wie leistungsfähig sind die Teilnehmer?}

Rosenberger, $F_{.1,2}$; Schembri, E. ${ }^{1,2}$; Heining, $\mathrm{C} .^{2,3}$; Steindorf, $\mathrm{K}^{4}$; Wiskemann, J. ${ }^{1}$

${ }^{1}$ AG Onkologische Sport- und Bewegungstherapie, Abteilung Medizinische Onkologie, Nationales Centrum für Tumorerkrankungen (NCT) und Universitätsklinikum Heidelberg,

${ }^{2}$ Deutsche Hochschule für Prävention und Gesundheitsmanagement DHfPG, Saarbrücken,

${ }^{3}$ Abteilung Translationale Onkologie, Nationales Centrum für Tumorerkrankungen (NCT) und Deutsches Krebsforschungszentrum (DKFZ) Heidelberg'

${ }^{4}$ Abteilung Bewegung, Präventionsforschung und Krebs, Nationales Centrum für Tumorerkrankungen (NCT) und Deutsches Krebsforschungszentrum (DKFZ), Heidelberg

Hintergrund: Körperliches Training wird onkologischen Patienten als supportive Therapiemaßnahme empfohlen [3]. Entsprechend bieten immer mehr onkologische Zentren sport- und bewegungstherapeutische Angebote an. Bislang wurde allerdings nicht systematisch untersucht, welche Charakteristika Patienten aufweisen, die an solchen Angeboten teilnehmen. Insbesondere Kenntnisse über die körperliche Leistungsfähigkeit erscheinen hilfreich, um weitere Angebote zielgruppenspezifisch gestalten zu können. Deshalb sollten die körperliche Leistungsfähigkeit und weitere Charakteristika der Teilnehmer der sport- und bewegungstherapeutischen Angebote am Nationalen Centrum für Tumorerkrankungen (NCT) Heidelberg analysiert werden. 
Methode: Es erfolgte eine Querschnittanalyse der Daten von $\mathrm{n}=1002$ onkologischen Patienten, die zwischen Mai 2012 und Februar 2016 außerhalb von Studien ein sport- und bewegungstherapeutisches Angebot am NCT Heidelberg (gerätegestütztes Krafttraining, Walking/Nordic Walking, Rudern, Rehabilitationssport, Training für Patienten mit Polyneuropathie, Beckenbodentraining, Entspannungstraining, Yoga, Stretching, Vermittlung an wohnortnahe Trainingszentren, Beratung zu Bewegung und Training) neu in Anspruch nahmen. Anthropometrische Daten, onkologische Diagnose und körperliches Aktivitätsverhalten vor sowie seit der onkologischen Diagnose wurden einem standardisierten Anamnesebogen des Beratungsdienstes «Bewegung und Krebs» entnommen. Daten zur körperlichen Leistungsfähigkeit, erfasst mittels Belastungs-Elektrokardiogramm oder Spiroergometrie, wurden sportmedizinischen oder kardiologischen Arztbriefen entnommen, die Patienten vor der Teilnahme an Angeboten mit intensiver Belastung vorlegten. Die Ergebnisse sind deskriptiv als Mittelwerte, Standardabweichungen und Spannen dargestellt. Unterschiede zwischen der erwarteten [1] und erreichten körperlichen Leistungsfähigkeit wurden mittels gepaartem t-Test verglichen.

Ergebnisse: Die Patienten waren zu 68\% weiblich, $55 \pm 13$ Jahre (13-86 Jahre) alt und hatten einen Body-Mass-Index (BMI) von $25 \pm 5 \mathrm{~kg} / \mathrm{m}^{2}$ $\left(15-60 \mathrm{~kg} / \mathrm{m}^{2}\right)$. Die häufigsten Tumorentitäten waren Mammakarzinom (43\%), Kolorektalkarzinom (8\%), andere gynäkologische Tumoren (6\%), Prostatakarzinom (5\%), ösophagogastrale Tumoren (5\%) und Pankreaskarzinom (5\%). 42\% der Patienten befanden sich in metastasierten Stadien $(n=1002)$. Vor Diagnose waren $41 \%$ der Patienten $2-3 \times$ wöchentlich körperlich aktiv und $16 \%$ gänzlich inaktiv. Seit Diagnose waren $25 \%$ der Patienten 2-3× wöchentlich körperlich aktiv und $45 \%$ gänzlich inaktiv (n = 926). Die maximale fahrradergometrische Leistung betrug 1,6 $\pm 0,6 \mathrm{~W} /$ $\mathrm{kg}(0,3-3,7 \mathrm{~W} / \mathrm{kg})$. Die maximale Sauerstoffaufnahme $\left(\mathrm{VO}_{2 \text { peak }}\right)$ lag bei 23 $\pm 7 \mathrm{ml} / \mathrm{min} / \mathrm{kg}(6-47 \mathrm{ml} / \mathrm{min} / \mathrm{kg})$, was um $-22 \pm 20 \%(-79-+43 \%)$ vom erwarteten Wert abweicht $(\mathrm{p}<0,001, \mathrm{n}=365)$.

Schlussfolgerung: Der hohe Anteil an weiblichen Teilnehmern bestätigt frühere Beobachtungen, dass Frauen häufiger an gesundheitsförderlichen Interventionsangeboten teilnehmen als Männer (2). Allerdings könnte der hohe Anteil an Mammakarzinompatientinnen dadurch beeinflusst sein, dass im Erhebungszeitraum Trainingsinterventionsstudien für diese Population durchgeführt wurden und dadurch in der gynäkologischen Ambulanz vermehrt Aufmerksamkeit auf die sport-und bewegungstherapeutischen Angebote gerichtet war. Die im Mittel deutlich reduzierte körperliche Leistungsfähigkeit zeigt, dass nicht nur trainierte Patienten die Angebote nutzten. Auffällig sind die weiten Spannen von Alter, BMI und körperlicher Leistungsfähigkeit. Sport- und bewegungstherapeutische Angebote an onkologischen Zentren sollten daher individuelle Betreuungs-, Vermittlungs- und Beratungsmöglichkeiten umfassen.

\section{Literatur}

1. Hansen J, Sue D \& Wasserman K. Predicted values for clinical exercise testing. Am Rev Resp Dis 1984;129:49-55.

2. Robroek SJ, van Lenthe FJ, van Empelen P \& Burdorf A. Determinants of participation in worksite health promotion programmes: a systematic review. Int $J$ Behav Nutr Phys Act 2009;6:26.

3. Schmitz KH, Courneya KS, Matthews C, Demark-Wahnefried W, Galvao DA, Pinto BM, Irwin ML, Wolin KY, Segal RJ, Lucia A, Schneider CM, von Gruenigen VE \& Schwartz AL. American College of Sports Medicine roundtable on exercise guidelines for cancer survivors. Med Sci Sports Exerc 2010;42(7):1409-1426.

Interessenkonflikte: Die Autoren haben keinen Interessenskonflikt.

\section{SB6 \\ LIBRE- Pilot: Ergebnisse der Trainingsintervention der Machbarkeitsstudie zur Lebensstilintervention bei erkrankten und gesunden BRCA1/2 Mutationsträgerinnen}

\author{
Berling-Ernst, A. ${ }^{1}$; Kiechle, M. ${ }^{2}$; Dukatz, . $^{2}{ }^{2}$ Yahiaoui-Doktor, M. ${ }^{3}$, \\ Basrai, $M^{4}$; Halle, M. ${ }^{1,5,6}$
}

${ }^{1}$ Lehrstuhl für Präventive und Rehabilitative Sportmedizin, Klinikum rechts der Isar, Technische Universität München, München,

${ }^{2}$ Lehrstuhl für Gynäkologie und Geburtshilfe, Klinikum rechts der Isar, Technische Universität München, München,

${ }^{3}$ Institut für medizinische Informatik, Statistik und Epidemiologie, Universität Leipzig, Leipzig,

${ }^{5}$ DZHK (German Centre for Cardiovascular Research), partner site Munich Heart Alliance, Munich, Germany,

${ }^{6}$ Else Kröner-Fresenius-Zentrum, Klinikum rechts der Isar, Munich, Germany

Hintergrund: Frauen mit einer BRCA1/2 Mutation haben ein 60-80\%iges Risiko im Laufe ihres Lebens an genetisch bedingtem Brust- oder Eierstockkrebs zu erkranken. Aktuellen Studien zufolge kann durch regelmäßige körperliche Aktivität die Brustkrebsinzidenz bei Frauen um durchschnittlich 25-30\% gesenkt werden. Bereits erkrankte Frauen können durch regelmäßige körperliche Aktivität entscheidend ihre Lebensqualität verbessern, therapiebedingte Nebenwirkungen lindern und sogar das Rezidivrisiko und die Mortalität um bis zu 50\% reduzieren. Außerdem wurden insbesondere für das mediterrane Ernährungsmuster günstige Effekte auf Tumorinzidenz und Erkrankungsverlauf beschrieben. Ob sowohl gesunde als auch erkrankte BRCA1/2 Mutationsträgerinnen gleichermaßen von einer Intervention hin zu einem aktiven und gesunden Lebensstil profitieren ist bislang unklar und soll in der LIBRE-Studie genauer analysiert werden.

Methoden: Im Vorfeld zur Hauptstudie (3 Jahre, $\mathrm{N}=600$ ) wurde die LIBRE-Pilot Studie (1 Jahr, N = 68) zum Aufzeigen der Machbarkeit durchgeführt. Die randomisiert (1:1), kontrollierte, multizentrische Machbarkeitsstudie umfasst $\mathrm{N}=68$ gesunde und bereits erkrankte BRCA1/2 Mutationsträgerinnen. Alle Teilnehmerinnen erhielten zum Studienbeginn (SE), nach 3 Monaten (V1) und nach 12 Monaten (V2) eine spiroergometrische Untersuchung (Rampenprotokoll). Zusätzlich wurde zu vier Messzeitpunkten SE, V1, zwischen dem 6. und 9. Monat (V1-6/9) und V2 die körperliche Aktivität objektiv über Akzelerometer (Aipermon500) und subjektiv über Aktivitätsfragebögen (IPAQ) erfasst. Erhoben wurden das Physical Activity Level (PAL-Wert), die MET-h, die maximale Sauerstoffaufnahme (VO2max), die ventilatorische Schwelle (VT1), die maximale Wattleistung sowie weitere Ausbelastungsparameter (RER).

Die Interventionsgruppe (IG, $\mathrm{N}=33$ ) erhielt eine strukturierte Schulung zu mediterraner Ernährung, mit Gruppenterminen zweiwöchentlich zwischen SE und V1, und zwischen V1 und V2 monatlich. Zusätzlich erhielt die IG einen individuellen Trainingsplan basierend auf den Ergebnissen der Spiroergometrie und ein dreimonatiges kombiniertes Ausdauer- und Krafttraining das zweimal wöchentlich supervidiert am Trainingszentrum und einmal wöchentlich zu Hause stattfand. Ziel der Intervention war es die Teilnehmerinnen auf einen Energieumsatz von 18 MET-h pro Woche zu bringen und dabei mindestens zwei Trainingseinheiten pro Woche zu absolvieren was in Trainingstagbüchern protokolliert wurde. Die Kontrollgruppe (KG, $\mathrm{N}=35$ ) erhielt eine einmalige Informationsveranstaltung über den positiven Einfluss von körperlicher Aktivität bei Tumorerkrankungen sowie Informationen zu gesunder Ernährung nach den Empfehlungen der Deutschen Gesellschaft für Ernährung (DGE).

Die Machbarkeit der Pilotstudie war definiert durch eine Erfüllung von $>70 \%$ der Trainingsvorgaben und einer Drop Out Rate von $<30 \%$. Sekundäre Endpunkte waren unter anderem die Veränderungen an der ersten ventilatorischen Schwelle (VT1), die maximale Sauerstoffaufnahme (VO2peak), die körperliche Aktivität (IPAQ), die Lebensqualität (EORTC QLQ- C30-/BR23), der BMI $\left(\mathrm{kg} / \mathrm{m}^{2}\right)$ sowie die Adhärenz zur mediterranen Ernährung (MEDAS). In dieser Analyse wird die Umsetzung der Trainingsvorgaben dargestellt. 
Ergebnisse: Von N = 26 Probandinnen der IG (7 Drop Outs) erfüllten 21 die Trainingsvorgaben von über $70 \%$ innerhalb der ersten drei Monate. Über die Hälfte der Teilnehmerinnen erreichte zusätzlich den geforderten Trainingsumfang von 18 MET-h pro Woche. Weiter verbesserte sich die Interventionsgruppe unter der Bedingung der Ausbelastung (RER > 1,05) an der ventilatorischen Schwelle (VT1) nach der dreimonatigen intensiven Intervention im Median von 14 auf $15 \mathrm{ml} / \mathrm{kg} / \mathrm{min}$ wohingegen sich die Kontrollgruppe von 16 auf $15 \mathrm{ml} / \mathrm{kg} / \mathrm{min}$ verschlechterte $(\mathrm{p}=0,038)$. Die objektive Erfassung des Aktivitätslevels (PAL-Wert = Physical Aktivity Level) mittels Akzelerometer ergab ebenfalls einen signifikanten Unterschied zwischen den Gruppen. Die Interventionsgruppe erhöhte ihr Aktivitätslevel wohingegen die Kontrollgruppe sich nach einem Jahr im Vergleich zum Ausgangswert verschlechterte $(\mathrm{p}=0,043)$.

Die Auswertung des Aktivitätsfragebogens (IPAQ) ergab keine bedeutsamen Unterschiede im Studienverlauf zwischen den Gruppen.

Schlussfolgerung: Die Trainingsintervention ist für dieses Kollektiv machbar, sicher und umsetzbar, was sich in der Akzeptanz und Erfüllung der Trainingsvorgaben widerspiegelt. Weiter sind die signifikanten Verbesserungen der Interventionsgruppe an der ventilatorischen Schwelle nach drei Monaten ein erster Hinweis darauf, dass die Intervention auch bei diesem Kollektiv positive Effekte bewirkt. Das höhere Aktivitätslevel (PAL-Wert) der Interventionsgruppe auch noch 1 Jahr nach der intensiven Betreuung deutet auf die Nachhaltigkeit der Maßnahmen hin, die über die Studiendauer hinweg Bestand haben. Langfristig soll durch die Weiterführung der Hauptstudie und die Nachbeobachtung dieses Projekt als Basis zu standardisierten Präventionsempfehlungen bezüglich des Aktivitätsverhaltens und Lebensstils für BRCA1/2 Mutationsträgerinnen dienen.

Dieses Projekt wird durch die Deutsche Krebshilfe e.V. gefördert.

Interessenkonflikte: Von Seiten der Autoren ergeben sich keine potentiellen Interessenkonflikte.

SB7

\section{Auswirkungen eines kombinierten Kraft- und} Ausdauertrainings auf die körperliche Leistungsfähigkeit bei Bronchialkarzinompatienten im fortgeschrittenen Erkrankungsstadium: Vorläufige Ergebnisse der POSITIVEStudie Part III

Titz, C. ${ }^{1,2,5}$; Hummler, S. ${ }^{2,3,4}$; Thomas, M. ${ }^{2,4}$; Wiskemann, J. $^{5}$

${ }^{1}$ Nationales Centrum für Tumorerkrankungen (NCT) und Deutsches Krebsforschungszentrum Heidelberg,

${ }^{2}$ Innere Medizin/Onkologie, Thoraxklinik am Universitätsklinikum Heidelberg

${ }^{3}$ Pneumologie, Thoraxklinik am Universitätsklinikum Heidelberg,

${ }^{4}$ Translational Lung Research Center Heidelberg (TLRC), Deutsches Zentrum für Lungenforschung (DZL),

${ }^{5}$ Arbeitsgruppe Onkologische Sport- und Bewegungstherapie, Medizinische Onkologie, Nationales Centrum für Tumorerkrankungen (NCT) und Universitätsklinikum Heidelberg

Hintergrund: Bronchialkarzinompatienten im fortgeschrittenem Erkran kungsstadium leiden unter einer nicht heilbaren Erkrankung mit sehr be grenzter Prognose und zeitnahem Lebensende (mediane Überlebenszeit $<12$ Monate). Diese Patienten entwickeln im Verlauf ihrer Erkrankung Einschränkungen unterschiedlichsten Ausmaßes, welche häufig zu einer Reduktion der körperlichen Leistungsfähigkeit führen. Über die positiven Auswirkungen von körperlichem Training bei operablen Bronchialkarzinompatienten gibt es zahlreiche Veröffentlichungen. Hingegen ist die Effektivität einer bewegungstherapeutischen Intervention bei Bronchialkarzinompatienten im fortgeschrittenen Erkrankungsstadium weiterhin unklar.

Methode: Aufbauend auf zwei bereits durchgeführten Studien (Hummler et al., 2014; Kuehr/Wiskemann et al., 2014) werden aktuell in einer randomisiert kontrollierten Studie die Effekte eines strukturierten Kraftund Ausdauertrainings bei nicht operablen Bronchialkarzinompatienten untersucht. Die Patienten werden in eine Kontroll- oder Trainingsgruppe randomisiert. Die Teilnehmer beider Gruppen erhalten über den Zeit- raum von 24 Wochen über einen wöchentlichen Telefonkontakt erweiterte Beratung und Betreuung (Symptommanagement). Die Trainingsgruppe führt zusätzlich 3x/Woche ein individuell angepasstes kombiniertes Kraftund Ausdauertraining, sowohl zuhause als auch in einem wohnortnahen Trainingszentrum, durch. Die primären Endpunkte nach 12 Wochen umfassen Lebensqualität (FACT-L) und Fatigue (MFI). Die sekundären Endpunkte messen die Veränderung der körperlichen Leistungsfähigkeit, psychosoziale und immunologische Parameter, sowie das Gesamtüberleben. Die körperliche Leistungsfähigkeit wird durch einen isometrischen Muskelkrafttest der oberen und unteren Extremitäten und den SechsMinuten-Gehtest im Studienverlauf geprüft. Die Datenerhebung erfolgt bei Baseline und anschließend im Abstand von 12 Wochen $\mathrm{zu}$ insgesamt fünf Messzeitpunkten.

Ergebnisse: Zwischen November 2013 und Dezember 2016 wurde die Rekrutierung der POSITIVE-Studie Part III mit 232 Patienten (134 Männer, 98 Frauen; Durchschnittsalter 62.2 Jahre) abgeschlossen. Ein Vergleich der körperlichen Leistungsfähigkeit bei Studieneinschluss mit Muskelkraftwerten einer gesunden Referenzpopulation (Bohannon et al., 1997) zeigte bei unseren Patienten deutlich niedrigere Werte in den Beinstreckern (Frauen: 335 vs. $282 \pm 78.9$ Newton; Männer: 471 vs. $376 \pm 76.3$ Newton) und Hüftabduktoren (Frauen: 207 vs. $131 \pm 26.8$ Newton; Männer: 304 vs. $184 \pm 46.6$ Newton). Bei den Männern sind zudem signifikante Unterschiede gegenüber den Referenzdaten in den oberen Extremitäten zu beobachten ( 287 vs. $244 \pm 46.8$ Newton; $\mathrm{p}<0.01)$. Im Sechs-Minuten-Gehtest erreichten unsere Patienten bei Studieneinschluss signifikant niedrigere Werte (Frauen: 542 vs. $453 \pm 81$ Meter; Männer 621 vs. $503 \pm 76$ Meter; $\mathrm{p}<0.01)$ im Vergleich $\mathrm{zu}$ errechneten Normdaten (Enright et al., 1998)

Mit bislang 132 Patienten wurde die Leistungsdiagnostik nach 12 Wochen Intervention durchgeführt. Bei Patienten, die regelmäßig trainiert haben, sind nach 12 Wochen signifikante Unterschiede der isometrischen Maximalkraft der Armbeuger $(p=0.02)$ und der Beinstrecker $(p=0.03)$ gegenüber der Kontrollgruppe zu beobachten. Berücksichtigt man ausschließlich die Patienten, die regelmäßig in einem wohnortnahen Trainingszentrum trainiert haben, sind zusätzlich signifikante Unterschiede in den Beinbeugern $(\mathrm{p}=0.03)$ und den Hüftabduktoren $(\mathrm{p}=0.04) \mathrm{zu}$ beobachten. Für Patienten, die vor der Diagnose nicht körperlich aktiv gewesen sind, zeigen sich signifikante Unterschiede in der isometrischen Maximalkraft der Armbeuger $(\mathrm{p}=0.02)$, Beinstrecker $(\mathrm{p}<0.01)$ und Beinbeuger $(\mathrm{p}=0.03)$.

Schlussfolgerung: Die Defizite in Kraft- und Ausdauerleistungsfähigkeit der Patienten bei Studieneinschluss belegen die Ergebnisse unserer Pilotstudie (Hummler et al., 2014) und bekräftigen darüber hinaus die Bedeutung einer Bewegungsintervention. Die gute Adhärenz in 55\% der Patienten spricht für die Machbarkeit einer Bewegungsintervention bei Patienten in einer palliativen Erkrankungssituation. Zum jetzigen Zeitpunkt sind bei Patienten, die regelmäßig in einem Trainingszentrum trainiert haben, nach einem 12-wöchigen Training Verbesserungen in der isometrischen Maximalkraft verschiedener Muskelgruppen zu beobachten. Auch wenn die Patienten der Kontrollgruppe ihre gewohnten Aktivitäten fortführen durften, sprechen deutliche Kraftverluste in den genannten Muskelgruppen für ein individuell angepasstes, strukturiertes Kraft- und Ausdauertraining, wie es Patienten der Trainingsgruppe im Rahmen der Studie durchführen.

Interessenkonflikte: Von Seiten der Autoren ergeben sich keine potentiellen Interessenkonflikte. 
SB8

\section{Auswirkungen eines 6-monatigen Krafttrainings auf die körperliche Fitness bei Pankreaskarzinompatienten}

Clauss, D. ${ }^{1,2}$; Tjaden, C. ${ }^{3}$; Schneider, L. ; Hackert, T. ${ }^{3}$; Wiskemann, J. ${ }^{2 *}$; Steindorf, $K^{1}{ }^{*}$

${ }^{1}$ Abteilung Bewegung, Präventionsforschung und Krebs, Deutsches Krebsforschungszentrum (DKFZ) und Nationales Centrum für Tumorerkrankungen (NCT) Heidelberg,

${ }^{2}$ Abteilung Medizinische Onkologie, Nationales Centrum für

Tumorerkrankungen (NCT) und Universitätsklinikum Heidelberg,

${ }^{3}$ Klinik für Allgemein-, Viszeral- und Transplantationschirurgie,

Universitätsklinikum Heidelberg

\section{* Geteilte Letztautorenschaft}

Hintergrund Es ist bekannt, dass systematisches körperliches Training die Fitness von Krebserkrankten verbessern kann. Zum aktuellen Zeitpunkt liegen jedoch keine klinischen Studien im Bereich des Pankreaskarzinom vor Aus diesem Grund führten wir eine randomisierte kontrollierte Interventionsstudie bei Pankreaskarzinompatienten durch. Ziel war es, die Machbarkeit und den Effekt eines 6-monatigen Krafttrainings zu untersuchen.

Methode Insgesamt wurden 65 Pankreaskarzinompatienten in der frühen Therapiephase (im Median 95 Tage nach Resektion) eingeschlossen und in drei Gruppen randomisiert: supervidiertes Krafttraining (EX1) Heimtraining (EX2), Standardbehandlungsarm (KG). Beide Interventionsgruppen führten zwei Mal pro Woche jeweils 60 Minuten für 6 Monate ein Krafttraining durch. EX1 führte ein moderates bis hoch intensives progressives Krafttraining unter therapeutischer Aufsicht durch. EX2 führte anhand eines Übungsmanuals die Übungen mit dem eigenen Körpergewicht oder mit Kleingeräten zu Hause durch und wurde einmal pro Woche telefonisch von einem Therapeuten betreut. KG erhielt keine Intervention. Maximale isometrische Muskelkraft (MVIC) und maximale isokinetische Muskelkraft (MIPT; stationäre Dynamometrie, 60\% die Streckung und Beugung der Knie, der Ellbogen und der Hüfte sowie kardiorespiratorische Fitnessparameter (Spiroergometrie) wurden zu Beginn und am Ende der Interventionsphase erhoben. Für die statistischen Auswertungen wurden Mixed-Modelle adjustiert auf die Ausgangswerte eingesetzt, um die Gruppenunterschiede zu analysieren.

Ergebnisse Von 65 Patienten (38 Männer, 27 Frauen; mittleres Alter: 61,7 Jahre; Stadium I-IV) beendeten 47 Patienten die Interventionsphase, wobei 4 Patienten aufgrund medizinischer Komplikationen keine Leistungsdiagnostik durchführen konnten. Es wurden insgesamt 59\% der vorgegebenen Trainingseinheiten absolviert. Diejenigen, die die Intervention beendeten, hatten eine Trainingsadhärenz von $72 \%$ der vorgegebenen Trainingseinheiten. Diese Patienten zeigten eine signifikante Verbesse rung der isokinetischen Maximalkraft der Armbeugung (EX1: $+6.3 \mathrm{Nm}$, 95\%CI $[2.7,9.8], \mathrm{KG}:+0.6 \mathrm{Nm}, 95 \% \mathrm{CI}[-2.3,3.4]$; ß 5.5 ; p-Werte für Gruppenvergleiche $\mathrm{p}=0.01)$ und Armstreckung $(\mathrm{EX} 1:+7.0 \mathrm{Nm}, 95 \% \mathrm{CI}$ [3.1, 10.9], KG: $+0.7 \mathrm{Nm}, 95 \% \mathrm{CI}[-2.4,3.8]$; $ß 6.5$; $\mathrm{p}=0.01)$ für EX1 im Vergleich zu KG als auch im Vergleich zu EX2 (Armbeugung: $+1.8 \mathrm{Nm}$, 95\%CI $[-0.7,4.3]$; $ß 4.3$; $\mathrm{p}=0.04$, Armstreckung: $+1.7 \mathrm{Nm}, 95 \% \mathrm{CI}[-1.1$, $4.4]$; $ß 5.5 ; \mathrm{p}=0.02)$. Für die isometrische Maximalkraft der Kniestreckung konnten signifikante Verbesserungen für EX1 $(\mathrm{EX} 1:+13.5 \mathrm{Nm}$, 95\%CI $[-4.5,31.6], \mathrm{KG}:-17.9 \mathrm{Nm}, 95 \% \mathrm{CI}[-32.8,-3.1] ;$ ß 34.5; $\mathrm{p}=0.0048)$ und EX2 $(+2.4 \mathrm{Nm}, 95 \% \mathrm{CI}[-10.2,15.0] ; ß 20.7 ; \mathrm{p}=0.04)$ im Vergleich zur KG beobachtet werden. Für die kardiorespiratorischen Fitnessparameter zeigte sich eine signifikante Verbesserung bei der maximalen Leistung (W) für EX1 im Vergleich zur KG (EX1: 19.1Nm, 95\%CI [8.8, 29.3]; ß 15.6; $\mathrm{p}=0.02$ ). Für die anderen kardiopulmonalen Parameter (maximale Sauerstoffaufnahme, ventilatorische Schwelle, Ventilation, respiratorischer Quotient und Herzfrequenz) zeigten sich keine unterschiedlichen Veränderungen zwischen den Gruppen.

Schlussfolgerung Wir konnten zeigen, dass ein Krafttraining bei Pankreaskarzinompatienten machbar ist. Die Muskelkraft konnte durch ein regelmäßig durchgeführtes Krafttraining bei Patienten mit Pankreaskarzinom verbessert werden, wobei ein supervidiertes Training effektiver zu sein scheint als ein Heimtraining.

Interessenkonflikte: Die Autoren geben an, keine Interessenkonflikte zu haben.

\section{SB9 \\ "Aktiv in der Nachsorge» - Erste Evaluationsergebnisse des Bewegungs-Motivationsprogramms für onkologische Patienten nach abgeschlossener Akuttherapie}

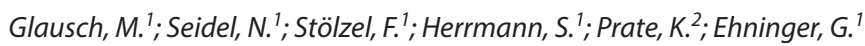
${ }^{1}$ Präventions- und Bildungszentrum des Universitäts KrebsCentrums Dresden (UCC),

${ }^{2}$ Universitäts-Physiotherapie-Zentrum (UPZ), Universitätsklinikum Carl Gustav Carus

Hintergrund: Regelmäßige körperliche Aktivität hat zahlreiche positive physische und psychische Effekte auf die Gesundheit von Tumorpatienten und wird daher von Fachgesellschaften ausdrücklich empfohlen [1]. Nordamerikanische Studien deuten jedoch darauf hin, dass sich Tumorpatienten nach Abschluss der Krebsbehandlung nicht ausreichend bewegen [2, 3]. Das Präventions- und Bildungszentrum des Universitäts KrebsCentrums Dresden entwickelte in Kooperation mit dem Nationalen Centrum für Tumorerkrankungen (NCT) in Heidelberg das «Aktiv in der Nachsorge - Bewegungs-Motivationsprogramm (AidN), mit dem Ziel, onkologische Patienten nach der Akuttherapie bei der Entwicklung und vor allem Aufrechterhaltung eines aktiven Lebensstils, zu unterstützen.

Methode: AidN ist ein sechsmonatiges Gruppenangebot bestehend aus Bewegungs- und Motivationseinheiten. In den Motivationseinheiten lernen die Teilnehmer Selbstmanagement-Strategien zur Umsetzung und Aufrechterhaltung eines körperlich aktiven Lebensstils (z. B. Setzen von Gesundheitszielen sowie Einsatz von Bewegungsplänen- und Protokollen), basierend auf dem Health Action Process Approach (HAPA) nach Schwarzer [4] kennen. Die Bewegungseinheiten bieten ein vielfältiges Sportangebot (z.B. Nordic Walking, Yoga, Krafttraining), welches die Patienten darin unterstützt, einen für sie passenden Sport zu finden. In den ersten vier Monaten finden die Termine wöchentlich, im fünften und sechsten Monat vierwöchentlich statt.

In einer Pilotstudie wurden die Zufriedenheit mit dem AidN-Programm und Effekte einer Teilnahme auf motivationale und volitionale Komponenten sowie körperliche Aktivität und Leistungsfähigkeit untersucht. 2016 nahmen in vier Kursen insgesamt 42 Patienten teil. Die Teilnehmer (71\% Frauen) waren im Mittel 60,8 Jahre alt (SD = 11,9; Range $=28-78$ Jahre). Die häufigsten Tumordiagnosen waren Mammakarzinome (32\%), hämatologische Erkrankungen (24\%) und Prostatakarzinome (10\%).

Ergebnisse: Insgesamt hat den Teilnehmern AidN gut bis sehr gut gefallen (100\%). Zu Beginn des Programms gaben 45\% der Teilnehmer an, nicht ausreichend (d.h. mindestens 150 Minuten pro Woche) körperlich aktiv zu sein. Im Prä-Post-Vergleich zeigte sich ein großer Effekt hin zu mehr körperlicher Aktivität (Mdn Prä 4,0, Mdn Post 5,0; $\mathrm{z}=-3,84, \mathrm{p}<0.01$, $r=0.71)$. Den Teilnehmern fiel es am Ende des Programms deutlich leichter, aktiv zu sein (Prä 13\%, Post 52\%). Als stärkste Hindernisse zur Ausübung eines körperlich aktiven Lebensstils gaben die Teilnehmer zur Prä-Erhebung motivationale Gründe an (38\% ,innerer Schweinehund', $33 \%$,keine Lust'). Weitere stark empfundene Barrieren standen besonders im Zusammenhang mit der Krebserkrankung bzw. -therapie oder anderen Erkrankungen (28\% , andere chronische Krankheiten', je 23\% ,Müdigkeit', ,Kräftemangel', und ,Schmerzen'). Beim Prä-Post Vergleich zeigt sich eine signifikante Abnahme der Barrieren außer , andere chronische Krankheiten' und ,Schmerzen', mit einem großen Effekt bei ,keine Lust' $(\mathrm{p}<0.01$, $r=0.65)$ und ,innerer Schweinehund' $(p<0.01, r=0.56)$.

In Bezug auf die körperliche Leistungsfähigkeit hatte AidN große Effekte. Der 6-Minuten-Gehtest stieg von $544 \pm 61$ auf $601 \pm 58(\mathrm{p}<0.01, \mathrm{r}=0.93)$ und der Sit-to-stand Test von $22 \pm 5$ auf $29 \pm 8(\mathrm{p}<0.01 ; \mathrm{r}=0.80)$.

Schlussfolgerung: Den Teilnehmern gelang es, während des Programms einen körperlich aktiven Lebensstil zu entwickeln. Insgesamt belegt die deutliche Abnahme der motivationalen Barrieren die Bedeutsamkeit von Selbstmanagement-Strategien in Bewegungsangeboten für Tumorpatienten. Die starken Barrieren im Zusammenhang mit der Krebserkrankung bzw. -therapie unterstreicht den Bedarf von Bewegungsangeboten speziell für onkologische Patienten. Mit Hilfe eines Follow-ups soll untersucht werden, ob der körperlich aktive Lebensstil längerfristig aufrechterhalten wird. 


\section{Literatur}

1. Schmitz, K. H., Courneya, K. S., Matthews, C., Demark-Wahnefried, W. Galvão, D. A., Pinto, B. M. et al. (2010). American College of Sports Medicine roundtable on exercise guidelines for cancer survivors. Medicine and Science in Sports and Exercise, 42(7):1409-1426.

2. Devoogdt, N., van Kampen, M., Geraerts, I., Coremans, T., Fieuws, S., Lefevre, J. et al. (2010). Physical activity levels after treatment for breast cancer: oneyear follow-up. Breast Cancer Research and Treatment, 123(2):417-425.

3. Courneya, K. S. \& Friedenreich, C. M. (1997). Relationship between exercise pattern across the cancer experience and current quality of life in colorectal cancer survivors. Journal of Alternative and Complementary Medicine, 3 (3):215-226.

4. Schwarzer (2008). Modeling Health Behavior Change: How to Predict and Modify the Adoption and Maintenance of Health Behaviors. Applied Psychology, $57: 1-29$.

Interessenkonflikte: Bei den Autoren liegen keine Interessenkonflikte vor.

SB10

\section{Hoch-intensives Kraft-/Ausdauertraining erhöht die antioxidative Kapazität im Muskel von BRCA Mutationsträgern (BIJOU-Studie)}

Otto, S.; Schumann, U.; Schulz, S.V.W.; Andreß, S.; Graf, T.; Steinacker, J.M.

Sektion Sport- und Rehabilitationsmedizin, Universitätsklinikum UIm, Deutschland

Hintergrund: Loss-of-function Mutationen im Tumorsuppressorgen BRCA1 führen zu einer Tumorwahrscheinlichkeit von $80 \%$ für Mammaund 40\% für Ovarialkarzinom vor dem 70. Lebensjahr. Durch Körperliche Aktivität und Vermeidung von Übergewicht in der Jugend kommt es zur Verzögerung von Brustkrebs bei BRCA Mutationsträgern. Aufgrund der zum jetzigen Zeitpunkt eingeschränkten primärpräventiven Möglichkei ten beim hereditären Mamma- und Ovarialkarzinom, welche oft einen erheblichen Eingriff in die Persönlichkeit bedeuten, sind BRCA Mutationsträger an alternativen Präventionsstrategien sehr interessiert. Neben seiner Funktion als Reparaturgen beschädigter DNA-Fragmente besitzt BRCA1 über die Interaktion mit Acetyl-CoA Carboxylase auch eine metabolische Muskelfunktion. Bei BRCA-Mutationsträgern kommt es durch die Aktivität der Acetyl-CoA-Carboxylase (ACC-p) und mittels Malonyl-CoA zu einer de novo Synthese von freien Fettsäuren (FS), die jedoch nicht verstoffwechselt werden und sich stattdessen anreichern, was zu Lipidperoxidationen und freier Radikalbildung (ROS, engl. Reactive Oxygen Species) führt. Die erhöhte oxidative Belastung des betroffenen Gewebes fördert die Kanzerogenese und kann weitere vielfältige Gesundheitsstörungen zur Folge haben. Die BIJOU-Studie untersucht, inwieweit ein hoch-intensives Kraft-/Ausdauertraining dem gestörten Fettstoffwechsel mit seinen nachteiligen Effekten entgegenwirkt und die antioxidative Kapazität im Muskel von BRCA Mutationsträgern erhöhen kann.

Methode: In dieser zweiarmigen, kontrollierten Kohortenstudie mit 16 Frauen und Männern (18- 69 Jahre) werden die Auswirkungen eines hochintensiven Kraft- und Intervallausdauer-trainings (IG) mit niedrig intensiven Entspannungsübungen (KG) jeweils an drei Tagen pro Woche über einen Gesamtzeitraum von 6 Wochen verglichen. Primär werden Veränderungen im Energiestoffwechsel anhand von Muskelbiopsien und Blutproben erhoben. Sekundäre Endpunkte beziehen sich auf Aktivitäten von Genen des Lipidstoffwechsels, molekulare Entzündungsmarker, Kraft- und Ausdauerleistungsfähigkeit (1-RM, VO2max), Lebensqualität (SF-36), Grad des Optimismus (LOT-R) und anthropometrische Daten.

Ergebnisse: Erste Ergebnisse an 13 Frauen und 3 Männern zeigen hoch signifikante Kraftverbesserungen $(+29 \%, \mathrm{p}<0,01)$ am Ruderkraftgerät von $46,6 \pm 19,31 \mathrm{~kg}$ auf $60,2 \pm 22,89 \mathrm{~kg}(\mathrm{MW} \pm \mathrm{SD})$ in der IG und keine Kraftveränderungen in der KG. An der Beinpresse verbesserten sich die Teilnehmer der IG hoch signifikant um 25,5\% (MW \pm SD: 146,1 \pm 58,05 $\mathrm{kg}, 183,3 \pm 57,81 \mathrm{~kg}$ ), während die Teilnehmer der KG zum Studienende beim 1-RM-Test im Mittel 3,33 kg $( \pm 13,06)$ weniger Last bewältigen konnten. Dieser Trend zeigte sich auch an den übrigen Kraftgeräten. Des Weiteren konnten signifikante Verbesserungen $(\mathrm{p}=0,015)$ der maximalen Ausdauerleistungsfähigkeit (VO2max) von $6 \%$ in der IG $(\mathrm{MW} \pm \mathrm{SD}$ : $2,03 \pm 0,39 \mathrm{l} / \mathrm{min}, 2,16 \pm 0,42 \mathrm{l} / \mathrm{min}$ ) entgegen einem Rückgang von $2,5 \%$ in der $\mathrm{KG}(\mathrm{MW} \pm \mathrm{SD}: 2,01 \pm 0,59 \mathrm{l} / \mathrm{min}, 1,97 \pm 0,56 \mathrm{l} / \mathrm{min})$ beobachtet werden. Die Leistung (P[Watt]) an der 3- bzw. 4-mmol-Laktatschwelle verbesserte sich in der IG hoch signifikant (jeweils $+25 \%$ ) und änderte sich nicht (P3 mmol/l[Watt]) bzw. unwesentlich $(+2 \%)$ in der KG (P4 $\mathrm{mmol} / \mathrm{l}[$ Watt]). Der Entzündungsmarker CRP bildete sich in der IG von 4,5 auf 1,9 mg/ml signifikant zurück, während er in der KG in der Tendenz leicht anstieg. Ferner stieg der Serum Thiol Status $(\mathrm{N}=13)$ in der IG von $611,27 \pm 114,9 \mu \mathrm{mol} / 1$ auf $667,89 \pm 85,3 \mu \mathrm{mol} / 1(\mathrm{MW} \pm \mathrm{SD})$ an, während er sich in der KG zurückbildete (MW \pm SD: $-34,58 \pm 21,53 \mu \mathrm{mol} / \mathrm{l})$. Die Waist-to-Hight-Ratio (WtHR) reduzierte sich im Mittel in der IG von $0,54 \pm 0,079 \mathrm{~cm}$ auf 0,53 $\pm 0,087 \mathrm{~cm}$ und erhöhte sich um den gleichen Wert in der KG. Auffallend war die hohe Akzeptanz der Studie, was sich in der Teilnahmehäufigkeit in beiden Gruppen wiederspiegelt (IG: 95\%, KG: $100 \%$ )

Schlussfolgerung: Erste Ergebnisse der BIJOU-Studie weisen auf eine Hochregulierung von Thiol als ROS Scavenger (Radikalfänger) hin. Durch intensives Training wird der Serumproteinstatus von Thiol erhöht. Dieser ist bei mehreren chronischen Krankheiten und auch bei Krebserkrankungen erniedrigt und reflektiert die gesamte DNA-Reparatur-Kapazität des Organismus durch Entgiftung von Sauerstoff, der freie Radikale enthält. Durch Verbesserungen des zellulären Metaboloms in dieser Hochrisikogruppe könnte der erhöhten Tumorentstehung bei BRCA-Mutationsträgern entgegen gewirkt werden.

Interessenkonflikte: Bei den Autoren liegt kein Interessenkonflikt vor.

SB11

\section{Effektivität einer strukturierten Intervention zur} Verbesserung der körperlichen Aktivität bei jungen Patienten nach überstandener Krebserkrankung im Kindes-, Jugendund jungen Erwachsenen Alter (AYAs)- eine randomisierte kontrollierte Studie- Motivate AYA - MAYA Studie

Salchow, J.; Jensen, W.; Koch, B.; Stein, A.; Bokemeyer, C.; Quidde, J. Hubertus Wald Tumorzentrum, Universitäres Cancer Center Hamburg (UCCH), Universitätsklinikum Hamburg- Eppendorf

Hintergrund: Zwei Drittel der jungen Patienten nach überstandener Krebserkrankung im Kindes-, Jugend- und jungen Erwachsenenalter (AYAs) leiden unter krankheits- oder therapiebedingten Folgeerkrankungen [1]. Zu den häufigsten Langzeitfolgen gehören die kardiovaskulären Erkrankungen, die ebenfalls die häufigste nichtmaligne Todesursache der AYAs repräsentieren [2, 3]. Im Vergleich zu der Normalbevölkerung ist bei AYAs das Risiko, eine Herzkreislauferkrankung zu entwickeln je nach Risikoprofil 5 bis 15-fach erhöht [1, 2, 4-7]. Eine retrospektive Kohortenstudie bei Langzeitüberlebenden nach Hodgkin Lymphom zeigte, dass anstrengende körperliche Aktivität mit mehr als 9 MET pro Woche, das Risiko für therapiebedingte kardiovaskuläre Erkrankungen verringert [8]. Das Ziel der vorliegenden Studie ist es daher, durch eine zusätzliche strukturierte Beratung zur körperlichen Aktivität und entsprechenden Empfehlungen, die Lebensqualität und Aktivität von AYA-Patienten zu verbessern, um damit Krankheitsfolgen zu senken und den (Wieder-)einstieg in das Berufsleben zu unterstützen.

Methode: In die derzeit laufende Studie werden im Rahmen des Survivorship-Programms am (UCCH) alle Patienten mit einer Krebsdiagnose im Kindes-, Jugend- und jungen Erwachsenen Alter (AYAs) in die Studie aufgenommen und in zwei Studienarme randomisiert. Die Interventionsgruppe (IG) erhält eine 45min. strukturierte Beratung zur körperlichen Aktivität (KA). Die Beratung beinhaltet die Erfassung der KA und Lebensqualität der AYAs mittels Fragebögen (IPAQ und EORTC QLQ-C30), spezielle Empfehlungen zur KA, sowie die Vermittlung von wohnortsnahen Sportangeboten. Im weiteren Verlauf werden die Patienten nach ein und drei Wochen weiterhin telefonisch beraten. Nach 12 Wochen erfolgt eine telefonische Kontaktaufnahme und die Zusendung der Fragebögen. Die Patienten in der Kontrollgruppe (KG) erhalten analog des aktuellen Standards im Rahmen der Survivorship-Sprechstunde allgemeine Empfehlungen zur KA und nach 12 Wochen den Fragebogen. Ein Follow-up 
zur Erfassung der längerfristigen Nachhaltigkeit der Intervention wird nach 12 Monaten durchgeführt.

Ergebnisse: Bislang wurden 52 Patienten in die Studie eingeschlossen, davon 23 Patienten in die IG und 29 Patienten in die KG. Das Durchschnittsalter der 32 Frauen und 20 Männern beträgt 23,8 \pm 5,9 Jahre. Insgesamt zeigen die Patienten in beiden Gruppen eine leichte Verbesserung ihres kognitiven und sozialen Funktionsstatus nach den Beratungen (spezielle Beratung zur KA sowie allgemeine Survivorship-Sprechstunde) $(\mathrm{p}<0,05)$. Die Patienten in der IG weisen nach 12-wöchiger Beratung höhere Werte in ihrer «Globalen Lebensqualität» auf. Die Werte vor der Beratung lagen bei 74,4 $\pm 12,0 \mathrm{im}$ Vergleich zu nach der Beratung bei $82,1 \pm 12,2$ $(p=0,021)$. Es konnte eine signifikante Verbesserung der intensiven körperlichen Aktivitäten der Patienten in der IG nach der 12-wöchigen Intervention beobachtet werden. Vor der Beratung führten die Patienten an $1,2 \pm 1,5$ Tagen pro Woche über $50 \pm 50,8$ min. intensive körperliche Aktivitäten durch. Nach der Beratung absolvierten die Patienten an 2,7 $\pm 1,1$ Tagen pro Woche über $96,0 \pm 36,2$ min. ihre intensiven Aktivitäten ( $\mathrm{p}=$ 0,006). Die Patienten in der IG verbrachten im Mittel 7,2 $\pm 3,6 \mathrm{~h}$ im Sitzen pro Tag. Nach der 12-wöchigen Intervention reduzierte sich die Zeit, die die Patienten im Sitzen verbracht hatten auf 5,5 $\pm 3,0 \mathrm{~h}(\mathrm{p}=0,038)$. Keine signifikanten Unterschiede konnten in der KG beobachtet werden. Im Rahmen eines individuell, angepasstem Trainingsprogramm für AYA-Patienten ist Krafttraining die Sportart, die die Patienten am ehesten ausführen möchten (18\%), gefolgt von Schwimmen (16\%), Fahrrad fahren (15\%), Yoga (14\%) und Ballspiele (11\%). Mehr als 50\% der Patienten würden an keinem Trainingsprogramm am UKE teilnehmen, da die Entfernung zum UKE zu weit ist. Weitere Daten werden erhoben und die Ergebnisse auf dem ASORS-Jahreskongress präsentiert.

Schlussfolgerung: Durch eine gezielte strukturierte und individuell angepasste Beratung zur körperlichen Aktivität kann sowohl die Lebensqualität verbessert als auch die körperlichen Aktivitäten der AYA- Patienten erhöht werden. Demnach sollte eine Beratung zur körperlichen Aktivität als Standard in das Nachsorgeprogramm von AYA-Patienten mit aufgenommen werden. Des Weiteren sollten Sportangebote flächendeckend im Raum Hamburg etabliert werden, um möglichst vielen AYA- Patienten Sportprogramme anbieten zu können.

Interessenkonflikte: Die Autoren erklären, dass kein Interessenkonflikt besteht.

\section{Literatur}

1. Oeffinger, K.C., et al.: Chronic health conditions in adult survivors of childhood cancer. New England Journal of Medicine, 2006. 355(15):1572-1582.

2. Mulrooney, D.A., et al.: Cardiac outcomes in a cohort of adult survivors of childhood and adolescent cancer: retrospective analysis of the Childhood Cancer Survivor Study cohort. British Medical Journal, 2009:339.

3. Castellino, S.M., et al.: Morbidity and mortality in long-term survivors of Hodgkin lymphoma: a report from the Childhood Cancer Survivor Study. Blood, 2011. 117(6):1806-1816

4. Tukenova, M., et al.: Role of cancer treatment in long-term overall and cardiovascular mortality after childhood cancer. J Clin Oncol, 2010. 28(8):1308-1315.

5. Armstrong, G.T., et al.: Modifiable risk factors and major cardiac events among adult survivors of childhood cancer. J Clin Oncol, 2013. 31(29):3673-3680.

6. Lipshultz, S.E., et al.: Long-term cardiovascular toxicity in children, adolescents, and young adults who receive cancer therapy: pathophysiology, course, monitoring, management, prevention, and research directions: a scientific statement from the American Heart Association. Circulation, 2013. 128(17):1927-1995.

7. Chao, C., et al.: Cardiovascular Disease Risk Profiles in Survivors of Adolescent and Young Adult (AYA) Cancer: The Kaiser Permanente AYA Cancer Survivors Study. J Clin Oncol, 2016.

8. Jones, L.W., et al.: Exercise and risk of major cardiovascular events in adult survivors of childhood hodgkin lymphoma: a report from the childhood cancer survivor study. J Clin Oncol, 2014. 32(32):3643-3650.
SB12

Motorische Einschränkungen von krebskranken Kindern nach stationärer Therapie am Beispiel des Springens

Rustler, V. ${ }^{1}$; Prokop, A. ${ }^{2}$; Bloch, W. ${ }^{1}$; Baumann, F.T. ${ }^{3}$; Däggelmann, J. ${ }^{1}$

${ }^{1}$ Institut für Kreislaufforschung und Sportmedizin, Abteilung Molekulare und Zelluläre Sportmedizin, Deutsche, Sporthochschule Köln,

${ }^{2}$ Kinderkrankenhaus Amsterdamer Straße Köln, Abteilung für Kinderonkologie und Hämatologie, Kliniken der Stadt Köln gGmbH,

${ }^{3}$ Centrum für Integrierte Onkologie Köln Bonn, Innere Medizin 1,

Universitätsklinikum Köln

Hintergrund: Das Bewegungsverhalten onkologisch erkrankter Kinder ist auch nach Therapieabschluss häufig durch körperliche Inaktivität gekennzeichnet. Verschiedene Studien verdeutlichen das eingeschränkte Aktivitätsverhalten u.a. anhand von Schrittzahlen und Gangzyklen. Kindliches Bewegungsverhalten ist jedoch vielschichtig und neben dem klassischen Gehen und Laufen durch weitere grundlegende motorische Fähigkeiten wie z.B. das Springen charakterisiert. Diese gilt es in der Kinderonkologie angemessen $\mathrm{zu}$ analysieren.

Methode: Im Kinderkrankenhaus Amsterdamer Straße, Köln haben 12 onkologisch erkrankte Kinder nach Abschluss der stationären Therapie (PG, ơ:8, $11.10 \pm 3.47$ Jahre, verschiedene Diagnosen, $\leq 5$ Jahre nach Therapieabschluss) sowie 12 gesunde Kinder (VG, ơ:8, $11.15 \pm 3.54$ Jahre, gematched in Alter und Geschlecht) an einer funktionell-motorischen Testung zur Erfassung der maximalen Sprungweite teilgenommen. Erfasst wurden die Sprungweite mit Hilfe des Standweitsprungs (SWS) sowie relevante funktionelle Fähigkeiten der unteren Extremität (Kraft der KnieExtensoren, aktive und passive Beweglichkeit im Sprunggelenk).

Ergebnisse: Im Matched-Pair-Vergleich zeigten sich signifikante Gruppenunterschiede im SWS ( $\mathrm{p}=0.041$ ) sowie in der Kraft der Knie-Extensoren $(\mathrm{p}=0.034)$ und der aktiven Beweglichkeit im Sprunggelenk $(\mathrm{p}=0.041) ;$ mit niedrigeren Werten in der PG. In der passiven Beweglichkeit des Sprunggelenks wurde kein signifikanter Unterschied nachgewiesen $(\mathrm{p}=0.071)$.

Schlussfolgerung: Die für das kindliche Bewegungsverhalten essentielle motorische Fähigkeit des Springens sowie funktionelle Fähigkeiten der unteren Extremität (Kraft der Knie-Extensoren, aktive Beweglichkeit im Sprunggelenk) scheinen bei onkologisch erkrankten Kindern eingeschränkt. Die eruierten funktionellen Einschränkungen können durch krankheits- und/oder therapiebedingte muskuloskeletale Probleme entstehen und stellen einen möglichen relevanten Grund für die Feststellung des Sprung-Defizits (SWS) dar. Am Beispiel des Springens soll die Notwendigkeit einer spezifischen Bewegungsförderung für krebskranke Kinder und Jugendliche betont werden. Denn vielseitige Bewegung ist ein Grundbedürfnis von Kindern. Durch Spiel, Sport und alltägliche Bewegung kann die Lebensqualität erhöht und die aktive Reintegration unterstützt werden. In zukünftigen Arbeiten sollten weitere grundlegende motorische Fähigkeiten berücksichtigt werden.

Interessenkonflikte: Es bestehen keine Interessenkonflikte seitens der Autoren.

\section{SB13}

\section{Prostatakrebspatienten unter Active Surveillance - Eine Chance nicht nur aktiv zu überwachen sondern auch körperlich aktiv zu werden}

\author{
Zopf, E.M. ${ }^{1,2,3}$; Bloch, W. ${ }^{3}$; Baumann, F.T. ${ }^{4}$ Shannon, $T^{5}$; Newton, R. ${ }^{2}$; \\ Galvao, D. ${ }^{2}$ \\ ${ }^{1}$ Australian Catholic University, Institute for Health and Ageing, \\ ${ }^{2}$ Edith Cowan University, Exercise Medicine Research Institute, \\ ${ }^{3}$ Deutsche Sporthochschule Köln, Institut für Kreislaufforschung und \\ Sportmedizin, \\ ${ }^{4}$ Universitätsklinikum Köln, Centrum für Integrierte Onkologie Köln Bonn, \\ ${ }^{5}$ Hollywood Private Hospital, Hollywood Specialist Centre
}

Hintergrund: Active Surveillance ist eine Strategie, die bei Patienten mit einem lokalem Low-Risk-Prostatakarzinom eingesetzt wird. Dabei wird die kurative medizinische Behandlung hinausgezögert, um das Risiko einer Übertherapie zu reduzieren und die Patienten möglichst lange von den behandlungsbedingten Nebenwirkungen zu verschonen. Diese Phase der 
aktiven Überwachung bietet die Chance, im Sinne der «Prehabilitation», vorab körperlich aktiv zu werden und somit den Körper und die Psyche zu stärken. Körperliche Aktivität hat sich in den letzten Jahren als sichere und effektive supportive Maßnahmen erwiesen, mit positiven Effekten auf physischer, psychischer und sozialer Ebene. Bis dato wurden jedoch alle bewegungstherapeutischen Interventionsstudien mit Prostatakrebspatienten während oder nach der medizinischen Therapie durchgeführt.

Methode: Um den Einfluss einer Bewegungsintervention auf Prostatakrebspatienten unter Active Surveillance zu untersuchen, wurde eine randomisiert-kontrollierte Pilotstudie zur Machbarkeit und Effektivität eines supervidierten Kraft- und Ausdauertrainings bei Prostatakrebspatienten unter Active Surveillance initiiert. In einer ersten explorativen Auswertung von acht Studienteilnehmern wurde die Entwicklung der physischen Fitness, der Körperkomposition, sowie des physischen und psychischen Wohlbefindens nach einer 3-monatigen Trainingsintervention mit drei Trainingseinheiten pro Woche untersucht.

Ergebnisse: Patienten in der Trainingsgruppe $(n=5)$ weisen eine positive Entwicklung im Bereich der physischen Fitness, der Körperkomposition sowie des psychischen Wohlbefindens auf. Dies spiegelt sich vor allem im Taillenumfang, der Beinkraft sowie dem psychischen Stressempfinden wider. Patienten in der Kontrollgruppe $(\mathrm{n}=3)$ weisen hingegen eine $\mathrm{Zu}$ nahme im Taillenumfang sowie geringere Veränderungen im Bereich der Muskelkraft und des psychischen Wohlbefindens auf.

Schlussfolgerung: Aufgrund von verbesserten diagnostischen Möglichkeiten werden immer mehr Prostatakrebserkrankungen im frühen Stadium diagnostiziert und die Active Surveillance-Strategie kommt zunehmend zum Einsatz. Erste Life-Style-Interventionsstudien und die dargestellten Beobachtungen deuten auf vielversprechende Effekte von körperlicher Aktivität in dieser Behandlungsphase hin. Die Aussagekraft dieser ersten Ergebnisse ist aufgrund der geringen Fallzahl limitiert, es schließt sich jedoch eine randomisiert-kontrollierte Studien mit größerer Fallzahl an diese Untersuchung an.

Interessenkonflikte: Das Projekt wurde von der Heinrich Hertz-Stiftung und der Edith Cowan University unterstützt. Es besteht kein Interessenkonflikt.

SU1

Lebensqualität bei Patienten mit ossär metastasiertem Mamma- oder Prostatakarzinom unter antiresorptiver Therapie

Werner, $T^{1}$; Jakob, A. ${ }^{2}$; Nusch, A. ${ }^{3}$; Sahlmann, J. ${ }^{4}$; Potthoff, $K^{4}{ }^{4}$

${ }^{1}$ Praxis für Urologie, Herzberg a.H.,

${ }^{2}$ Gemeinschaftspraxis für Hämatologie und Onkologie, Offenburg,

${ }^{3}$ Praxis für Hämatologie und internistische Onkologie, Ratingen,

${ }^{4}$ iOMEDICO, Freiburg

Hintergrund: Knochenmetastasen zählen zu den häufigsten Metastasen bei fortgeschrittenen Krebserkrankungen. Am häufigsten treten Knochenmetastasen vor allem bei Brustkrebs- und Prostatakarzinompatienten auf. Die damit einhergehenden Schmerzen sowie die «skeletal related events» (SRE) - Knochenfrakturen, Spinalkanalkompression, Bestrahlung, Chirurgie - haben gravierende Auswirkungen auf die Lebensqualität, die Morbidität und Mortalität der Patienten. Die Intention der Behandlung von Patienten mit Knochenmetastasen ist die Aufrechterhaltung oder Verbesserung der Lebensqualität. Ziel dieser Studie ist es, die Lebensqualität bei Mammakarzinom- und Prostatakarzinompatienten mit Knochenmetastasen, die eine antiresorptive Therapie erhalten, in Hinblick auf durch Knochenmetastasen hervorgerufene Beschwerden sowie Schmerzen und den Einfluss der Behandlung auf das Alltagsleben prospektiv und strukturiert zu untersuchen.

Methode: Zur Erfassung der «patient-reported outcomes» zu Lebensqualität bei Mammakarzinom- und Prostatakarzinompatienten mit Knochenmetastasen wurden der validierte «Functional Assessment of Cancer Therapy Bone Pain» (FACT-BP) Fragebogen sowie eine nummerische Rating-Skala (NRS) zum subjektiven Schmerzempfinden, zwei Fragen zur Schmerzmedikation und vier Fragen zum Einfluss der Behandlung auf das Alltagsleben eingesetzt. Der FACT-BP Fragebogen wurde speziell entwi- ckelt, um krebsbedingte Knochenschmerzen und deren Auswirkungen auf die Lebensqualität der Patienten zu untersuchen.

Die Patienten wurden zu Beginn ihrer ersten antiresorptiven Therapie aufgrund der Diagnose von Knochenmetastasen in die Studie eingeschlossen und für bis zu 12 Monate beobachtet. Zu Beginn und danach ca. monatlich beantworteten die Patienten die Fragebögen.

Interessenkonflikte: Es bestehen keine potenziellen Interessenkonflikte im Zusammenhang mit der Fa. AMGEN.

\section{SU2}

\section{Lebensqualität, geriatrisches Assessment und} pflegerische Nachsorge - Ergebnisse der Pilotierung eines patientenzentrierten interdisziplinären Behandlungs- und Versorgungskonzeptes für onkologisch-geriatrische Patienten (PIVOG)

\section{Schmidt, H. ${ }^{2}$; Lampe, K. ${ }^{1}$; Boese, S. ${ }^{2}$; Jordan, $K^{3}$; Müller-Werdan, U. ${ }^{4}$;} Vordermark, $D$.

${ }^{1}$ Universitätsklinik für Strahlentherapie, Universitätsklinikum Halle/Saale, ${ }^{2}$ Institut für Gesundheits- und Pflegewissenschaft, Medizinische Fakultät der Martin-Luther Universität Halle-Wittenberg,

${ }^{3}$ Universitätsklinik für Innere Medizin IV, Universitätsklinikum Halle/Saale,

${ }^{4}$ Evangelisches Geriatriezentrum / Charité Universitätsmedizin, Berlin

Fragestellung: Ältere onkologische Patienten unterscheiden sich bezüglich ihres biologischen Alters, der körperlichen und kognitiven Funktionalität sowie der Anzahl und Schwere ihrer Begleiterkrankungen. Um individuelle Risikofaktoren zu identifizieren, wird für die Planung der onkologischen Therapie das geriatrische Assessment (GA) empfohlen, Dies wird jedoch noch nicht konsequent im klinischen Alltag eingesetzt. Mit dem Ziel durch individuelle Betreuung die Lebensqualität der Patienten zu erhalten, wurden im Rahmen der Studie Machbarkeit und potentieller Nutzen einer komplexen Intervention mit GA, patientenberichteter Lebensqualität (HRQOL) und einer telefonischen pflegerischen Nachsorge untersucht.

Methodik: Zu Beginn der Behandlung wurden ergänzend zur ärztlichen und pflegerischen Aufnahme durch eine qualifizierte Pflegekraft und eine Physiotherapeutin Assessments zur Ernährung, Kognition, psychischen und sozialen Lage sowie HRQOL (EORTC QLQ C-30 und ELD 14) und Mobilität durchgeführt, um ein umfassendes Bild von Ressourcen und Einschränkungen der Patienten zu erhalten. Die Medikation wurde auf potentiell inadäquate Medikamente geprüft. Individuelle Ergebnisse der Assessments wurden nach einem Ampelprinzip kategorisiert und gezielte Supportivmaßnahmen eingeleitet. Nach Beendigung der Akuttherapie erhielten die Patienten eine telefonische pflegerische Nachbetreuung über 20 Wochen. Primärer Endpunkt: globale HRQOL (EORTC QLQ C-30 ) im 6 Monats-Follow-up. Sekundäre Endpunkte: Symptome und Funktionalität (EORTC QLQ C-30 und ELD 14), ungeplante Hospitalisierungen und Patientenzufriedenheit.

Ergebnisse: Es nahmen $\mathrm{n}=100$ Patienten (44\% der in Frage kommenden), Alter: MW 76,3 Jahre (SD 4,8), 53\% Männer, an der Studie teil. Die Teilnehmenden hatten im Mittel $\mathrm{n}=5$ Komorbiditäten (min. 1, max. 12), darunter am häufigsten Hypertonus (78\%) und nahmen im Mittel 8 Medikamente ein (min. 0 max. 15). Aufgrund der Eingangsassessments, die im Schnitt eine Stunde in Anspruch nahmen, wurden bei 66\% der Teilnehmer Einschränkungen der Mobilität, bei 61\% ein Risiko für Mangelernährung, bei 52\% Defizite der Versorgung und bei 44\% Niedergeschlagenheit oder Depression festgestellt. Darauf basierend wurden als therapiebegleitende Supportivmaßnahmen beispielsweise Physiotherapie, Psychoonkologische Betreuung, Ernährungs- und Sozialberatung sowie gezielte medikamentöse Therapien veranlasst. Die Medikamentenprüfung ergab 51 Änderungsempfehlungen. Die telefonische pflegerische Nachsorge wurde von den Patienten sehr gut angenommen. Häufigste Beratungsanlässe waren Schmerzen, Ernährungsprobleme wie Appetitlosigkeit, Fatigue, Schlafstörungen, Ängste, Krankheits- und Alltagsbewältigung, Kommunikation mit der Familie und Ärzten sowie der Kontakt zu Selbsthilfegruppen oder der Krebsberatung hergestellt. 
Im Follow-up sechs Monate nach Beendigung der Akuttherapie $(\mathrm{n}=57)$ war die globale HRQOL für 20 Patienten klinisch relevant verbessert (Diff. $\geq 10$ Punkte), für 21 unverändert und für 16 Patienten klinisch relevant verschlechtert. Auch bei unveränderter oder verbesserter globaler HRQOL zeigten sich jedoch klinisch relevante Verschlechterungen der Symptome und Funktionalität z.B. für Fatigue, Schmerz und Appetitlosigkeit sowie körperliche und Rollenfunktion.

Schlussfolgerung: Die Pilotphase zeigte Machbarkeit und potentiellen Nutzen der ergänzenden Assessments und der pflegerischen Nachsorge. Es besteht weiterer Forschungsbedarf bezüglich geschlechtsspezifischer Unterschiede von Symptomwahrnehmung und HRQOL sowie möglicher Einflussfaktoren auf die HRQOL. Zukünftige Studien sollten gezielte Interventionen zur Förderung der HRQOL und insbesondere der Mobilität als Basis der Alltagsfunktionalität prüfen.

Interessenkonflikte: Es bestehen keine potentiellen Interessenkonflikte.

\section{SU3}

\section{Einflussfaktoren und Charakteristika von physischer, affektiver und kognitiver Fatigue während und 12 Monate nach Brustkrebstherapie}

\section{Schmidt, M.E. ${ }^{1}$; Wiskemann, J. ${ }^{2}$; Schneeweiss, A. ${ }^{3}$; Potthoff, $K^{4}$;} Ulrich, C.M. ${ }^{5}$; Steindorf, K. ${ }^{1}$

${ }^{1}$ Abteilung Bewegung, Präventionsforschung und Krebs, Deutsches Krebsforschungszentrum (DKFZ) und Nationales Centrum für

Tumorerkrankungen (NCT), Heidelberg,

${ }^{2}$ Abteilung Medizinische Onkologie, Universitätsklinikum Heidelberg und Nationales Centrum für Tumorerkrankungen (NCT), Heidelberg,

${ }^{3}$ Sektion Gynäkologische Onkologie, Universitätsklinikum Heidelberg und Nationales Centrum für Tumorerkrankungen (NCT), Heidelberg,

${ }^{4}$ Radioonkologie, Universitätsklinikum Heidelberg und Nationales Centrum für Tumorerkrankungen (NCT), Heidelberg,

${ }^{5}$ Department of Population Health Sciences, Huntsman Cancer Institute and University of Utah, USA

Hintergrund: Fatigue ist ein häufiges und stark belastendes Symptom während und nach einer Krebstherapie. Um die derzeitige noch unbefriedigend Behandlungssituation zu verbessern, ist eine differenziertere Betrachtung nötig. Deshalb untersuchten wir potentielle Einflussfaktoren und Charakteristika von verschiedenen Fatiguedimensionen (physisch, affektiv, kognitiv) während und nach einer Brustkrebstherapie.

Methode: Im Rahmen einer 12-monatigen Nachbeobachtung von zwei randomisierten kontrollierten Interventionsstudien wurde Fatigue mit dem multidimensionalen 20-Item Fatigue Assessment Questionnaire bei 255 Brustkrebspatientinnen wiederholt erhoben. Als potentielle Determinanten der verschiedenen Fatiguedimensionen wurden klinische, soziodemographische, physische und psychische Faktoren mittels linearer gemischter Modelle untersucht.

Ergebnisse: Chemotherapie trug signifikant zum Anstieg der physischen Fatigue bei. Für das Fortbestehen der Fatigue ca. 12 Monate nach Therapieende spielte es allerdings keine signifikante Rolle, ob die Patientin eine Chemotherapie oder nur Strahlentherapie erhalten hatte. Sportliche Aktivität war durchgehend mit reduzierter physischer Fatigue assoziiert, während Adipositas und Übergewicht mit erhöhter physischer Fatigue einherging. Diese Faktoren zeigten dagegen keine wesentliche Assoziation mit affektiver Fatigue, die stattdessen mit Mangel an sozialer Unterstützung und Zukunftssorgen assoziiert war. Vorbestehende psychische Probleme, Schlafprobleme und auch Hitzewallungen waren dahingegen mit allen Fatiguedimensionen assoziiert.

Schlussfolgerung: Die oft pauschale Diagnose «krebsbedingte Fatigue» muss als ein vielschichtiges Syndrom betrachtet werden, dass durch unterschiedliche Faktoren, Charakteristika und Verläufe mit vermutlich unterschiedlichen Ätiologien bestimmt ist. Daher ist ein «one-fits-all» Therapieansatz nicht sinnvoll. Weitere Forschung zu effektiven Interventionen, die basierend auf einer genauen Fatigueanamnese individuell auf die jeweilige Patientensituation zugeschnitten werden, ist nötig.

Interessenkonflikte: Keiner der Autoren hat einen Interessenkonflikt.
SU4

\section{Schlafstörungen bei Tumorpatienten - Ein häufiges Symptom} mit behandelbaren Ursachen

Schnellen, S. ${ }^{1}$; Strik, H. ${ }^{1}$; Teepker, M. ${ }^{1}$; Kussin, A. ${ }^{2}$; Kluge, I. ${ }^{3}$; Seifart, U. ${ }^{4}$; Schulte, T. ${ }^{5}$; Riera-Knorrenschild, J. ${ }^{6}$; Koehler, U. ${ }^{7}$; Cassel, W. ${ }^{7}$

${ }^{1}$ Klinik für Neurologie, Philipps-University, Marburg,

${ }^{2}$ Klinik fürAnästhesie und Intensivmedizin, Philipps-Universität, Marburg,

${ }^{3}$ Klinik für Psychiatrie und Psychotherapie, Philipps-Universität, Marburg,

${ }^{4}$ Klinik Sonnenblick, Deutsche Rentenversicherung Bund, Marburg,

${ }^{5}$ Fachklinik onkologische Rehabilitation, Bad Oexen,

${ }^{6}$ Klinik für Hämatologie und Onkologie, Philipps-Universität, Marburg,

${ }^{7}$ Klinik für Innnere Medizin, Pulmonologie, Intensiv- und Schlafmedizin,

Philipps-Universität, Marburg

Schlafstörungen sind bei Tumorpatienten häufig und beeinträchtigen die Lebensqualität erheblich. Die Einflußfaktoren sind vielfältig, weshalb die vorliegende Studie sich zum Ziel gesetzt hat, umfassend die Korrelationen mit den wesentlichen zu erwartenden und anamnestisch abfragbaren Ursachen zu analysieren.

Hierzu wurden 107 Patienten mit unterschiedlichen Tumorentitäten mit einer ausführlichen Testbatterie auf Häufigkeit und Art von Schlafstörungen und ihre wichtigsten zu erwartenden Begleitfaktoren Depression, Angst, Schmerz, Grübelneigung, soziale Faktoren und Begleitmedikation befragt.

Etwa zwei Drittel (68\%) der befragten Patienten wiesen Anzeichen für eine bestimmte Art von Schlafstörung auf. Dabei zeigten die untersuchten organischen, psychologischen und sozialen Begleitfaktoren einen wesentlichen Einfluss auf die Schlafqualität. Die höchste Korrelation bestand zwischen einer Depression und Schlafstörungen (86,8\%), während immerhin noch 77,6\% der Schmerzpatienten Beeinträchtigungen des Schlafes angaben. Schmerzen $(59,2 \%)$ und Angst $(77,4 \%)$ wiederum korrelierten eng mit dem Auftreten einer depressiven Symptomatik. Allgemein nahmen Tumorpatienten mit Hinweisen für Schlafstörungen häufiger Medikamente ein und waren durch Grübelneigung bzw. negativ konnotierte Teilaspekte einer Krebserkrankung (aktive Behandlung, palliatives statt kuratives Behandlungskonzept) wesentlich beeinträchtigt. Auch psychosoziale Begleitfaktoren wie Sorgen um die finanzielle Situation ( $84 \%$ Schlafstörungen) und den Arbeitsplatz (89\%) hatten einen erheblichen Einfluß auf den Nachtschlaf.

Nach unserer Kenntnis ist dies die erste Studie mit einer solch umfangreichen Analyse von Schlafstörungen und korrelierenden Faktoren bei Tumorpatienten. Da für viele dieser Aspekte Behandlungsansätze zur Verfügung stehen ist eine Erfassung dieser Ursachen im klinischen Alltag sinnvoll. In einem derzeit in Planung befindlichen Folgeprojekt wird ein verkürzter Fragebogen als Selbstbeobachtungsinstrument für klinische Studien entwickelt sowie mehrere numerische Ratingskalen als Screeninginstrument für die klinische Praxis.

Interessenkonflikte: Es liegen keine Interessenkonflikte vor.

SU5

Tumor-Fatigue-Sprechstunde der Bayerischen

Krebsgesellschaft e.V. - Wo stehen wir und wie geht es weiter?

Fischer, I. ${ }^{1,3,4}$; Besseler, M. ${ }^{2,3}$; Heim, M.E. ${ }^{3,4,5}$; Koller, M. ${ }^{6}$; Riedner, C. ${ }^{3,7}$; Schlimok, G. ${ }^{2}$

${ }^{1}$ Institut für Tumor-Fatigue-Forschung (Emskirchen),

${ }^{2}$ Bayerische Krebsgesellschaft e.V. (München),

${ }^{3} \mathrm{AG} \mathrm{Tumor-Fatigue} \mathrm{in} \mathrm{der} \mathrm{BKG} \mathrm{e.V.} \mathrm{(München),}$

${ }^{4}$ Deutsche Fatigue Gesellschaft e.V. (Köln),

${ }^{5}$ Gesundheitszentrum Bodensee, Klinik Sokrates (CH-Güttingen),

${ }^{6}$ Zentrum für Klinische Studien, Universitätsklinikum Regensburg (Regensburg)

${ }^{7}$ Krebsberatungsstelle am Tumorzentrum München in Kooperation mit der

Bayerischen Krebsgesellschaft e.V. (München)

Hintergrund: Tumor-assoziierte Fatigue (cancer-related fatigue, CRF) ist ein atypischer, belastender Zustand von Müdigkeit, Erschöpfung und Energiemangel in zeitlichem und/ oder ursächlichem Zusammenhang mit einer Tumorerkrankung bzw. deren Therapie. CRF hat gravierende 
Auswirkungen auf die Alltagsfunktionalität und die Lebensqualität und ist mit einem kürzeren Gesamtüberleben assoziiert. Obwohl Methoden der (Differential-) Diagnostik und evidenzbasierte Therapien vorhanden sind und obwohl eine frühzeitige Behandlung das Chronifizierungsrisiko reduzieren kann, zeigen Studien, dass die Versorgung hinsichtlich CRF ein unerfüllter Bedarf vieler Krebspatienten ist. Dies gilt auch für Bayern. Die Bayerische Krebsgesellschaft e.V. (BKG) strebt daher in gemeinsam mit dem Institut für Tumor-Fatigue-Forschung (ITFF) durch das Angebot ärztlich geleiteter, kostenloser Tumor-Fatigue-Sprechstunden in Bayern den Aufbau einer flächendeckenden Versorgungsstruktur an. An dem Projekt beteiligt sind außer den Autoren auch Peter Bojko, Pia Heußner, Valeria Milani, Nina Rinas, Jens Ulrich Rüffer sowie Erhard Schneider. Im Rahmen einer ersten Pilotphase (09-12/ 2013) wurde in der Psychosozialen Krebsberatungs-stelle (KBS) Nürnberg der BKG e.V. CRF-Sprechstunden angeboten. In der darauf aufbauenden Pilotphase II (Januar 2014 - Dezember 2014) wurden die Abläufe kontinuierlich weiterentwickelt und standardisiert. Seit Januar 2015 wird die CRF-Sprechstunde «nach dem Nürnberger Modell» unter jeweils ärztlicher Leitung auch in Bayreuth, Kempten, München und bei einer externen Kooperationspartnerin in Fürstenfeldbruck angeboten. Alle Ärzte wurden intensiv auf ihre Tätigkeit vorbereitet und es besteht die Möglichkeit zur gegenseitigen Supervision.

Methode: Die Sprechstunde umfasst (Differential-) Diagnostik und eine darauf aufbauende individualisierte Beratung. Wichtigstes diagnostisches Instrument ist der Anamneseleitfaden der Deutschen Fatigue Gesellschaft. Ergänzend werden psychometrische Fragebögen (Brief Fatigue Inventory [BFI], zeitlicher Bezugsrahmen: letzte 7 Tage; HADS-D) verwendet und es erfolgt Einsicht in Patientenunterlagen. In der Beratung werden die Patienten über CRF informiert, der Befund wird besprochen und für den Patienten geeignete Interventionen (mit Evidenz raus randomisierten Studien, systematischen Reviews und Meta-Analysen) werden erläutert. Im Sinne der partizipatorischen Entscheidungsfindung wird dann gemeinsam mit dem Patienten die weitere Vorgehensweise festgelegt. Zur Umsetzung symptomatischer nicht-medikamentöser Interventionen werden in den Krebsberatungsstellen geeignete Kursen angeboten (z.B. Yoga, Qigong) und die Patienten können psychoonkologisch/ psychosozial beraten werden. Alle anderen Maßnahmen (z.B. weiterführende Diagnostik, Therapie von Komorbiditäten, symptomatische medikamentöse Therapien der CRF) erfolgen durch den zuständigen Arzt, dem eine Zusammenarbeit angeboten wird. Zu diesem Zweck erhalten die Patienten ein handschriftlich ergänztes Formblatt mit allen Empfehlungen und den Kontaktdaten der Sprechstunde. Diagnostik und Beratung werden systematisch dokumentiert. Alle Sprechstunden wurden von September 2013 bis Dezember 2015 extern evaluiert.

Ergebnisse: Ergebnisse liegen derzeit für den Zeitraum September 2013 bis Dezember 2015 vor. In dieser Zeit wurde die Sprechstunde von 269, überwiegend weiblichen Patienten genutzt. Die häufigste Diagnose war Brustkrebs. 64\% der Patienten wiesen im BFI eine moderate, 31\% eine schwere Fatigue auf. Bei 7\% begann die CRF mindestens 3 Jahre vor, bei 16\% 3-21 Jahre nach der Tumorerstdiagnose. 55\% der Patienten berichteten, täglich von der CRF betroffen zu sein. 57\% gaben im BFI eine moderate, $44 \%$ eine schwere Beeinträchtigung an. $21 \%$ der Patienten berichteten, durch die CRF gehindert zu sein, ärztliche Empfehlungen zu befolgen. Fast alle Patienten fühlten sich durch die CRF psychisch stark belastet ( $46 \%$ schwer, $41 \%$ moderat).

251 der 269 Patienten beteiligten sich an der Evaluation (Rücklaufquote: 93\%). Die Sprechstunde wurde in den offenen und in den geschlossenen Fragen hinsichtlich Inhalt, Umfang und Gestaltung von den Patienten sehr gut bewertet und erhielt insgesamt die Durchschnitts-Schulnote von 1,2 .

Schlussfolgerung: Es hat sich gezeigt, dass Bedarf für eine Tumor-Fatigue-Sprechstunde vorhanden ist, dass sie angenommen und von den Patienten als sehr gut bewertet wird. Um dem Patienten-Wunsch nach einer wohnortnahen Versorgung zu entsprechen, sollen (vorbehaltlich der Finanzierbarkeit) zusätzlich zum bisherigen Angebot identische Sprechstunden auch in den KBS Augsburg, Ingolstadt, Regensburg, Passau und Würzburg eingerichtet werden. In der Endstufe sollen alle Sprechstunden nach Möglichkeit von Ärzten mit onkologischer und psychoonkologi- scher Erfahrung geleitet werden. Dies entspricht nicht nur dem Wunsch der Patienten nach nur einem Ansprechpartner, sondern auch der Notwendigkeit einer niedrigschwelligen, ressourcen-schonenden Versorgung. Um zu eruieren, ob durch die Sprechstunde auch längerfristig die Situation der Patienten hinsichtlich CRF und Lebensqualität verbessern kann, soll eine Längsschnittstudie durchgeführt werden.

Interessenkonflikte: Es bestehen keine Interessenkonflikte.

\section{SU6}

\section{Chemotherapie-induzierte Nausea und Emesis - sind die allgemeinen Leitlinien in der Neuroonkologie sinnvoll?}

Just, L.; Rock, H.; Strik, $H$.

Neurologische Klinik, Philipps Universität Marburg

Hintergrund: Temozolomid, das am häufigsten eingesetzte Chemotherapeutikum in der Neuroonkologie, hat lediglich ein moderat emetogenes Potential. Aus diesem Grund sieht eine Vielzahl der Neuroonkologen keine Notwendigkeit zur Umsetzung der MASCC-Leitlinien, welche die Gabe von Palonosetron und Dexamethason zur antiemetischen Prophylaxe empfehlen. Zudem wird Dexamethason außerhalb der Hirnödembehandlung nur sehr restriktiv eingesetzt wird zur Vermeidung gravierender Langzeitnebenwirkungen.

Methoden: Für die vorliegende Studie wurde das MASCC Antiemese Werkzeug um eine numerische Schätzskala mit 11 Stufen von «0»-keine Übelkeit bis «10»- extreme Übelkeit, ausgelegt für 10 Untersuchungstage, erweitert. Mit den Fragebögen EORTC QLQ-C30 und QLQ-BN20 und dem PHQ-9 wurde außerdem die Lebensqualität erfasst. Bislang wurden 78 Patienten eingeschlossen und über zwei Zyklen beobachtet.

Ergebnisse: Die Temozolomiddosen bewegten sich zwischen $50 \mathrm{mg} / \mathrm{m}^{2} / \mathrm{d}$ und $360 \mathrm{mg} / \mathrm{m}^{2} / \mathrm{d}$ und wurden an Tag 1-5 eines Zyklus verabreicht. Die verwendeten Antiemetika waren Alizaprid $50 \mathrm{mg}$, Ondansetron $8 \mathrm{mg}$, Granisetron $2 \mathrm{mg}$ and Dronabinol, jeweils appliziert Tag 1-5/5, oder Palonosetrone $0.5 \mathrm{mg}$ Tag 1.

Entgegen der Erwartungen können auch geringe Temozolomiddosen von unter $100 \mathrm{mg} / \mathrm{m}^{2} / \mathrm{d}$ massive Übelkeit mit Werten von 10/10 auf der Schätzskala auslösen. Unter Alizaprid (18 Patienten) wurden maximale Werte von 10/10 beobachtet, aber auch unter Therapie mit Ondansetron (41 Patienten) und Granisetron (12 Patienten) fand sich massive Übelkeit. Unter Palonosetron (6 Patienten) lag der maximale Wert bei 8/10. Unabhängig vom angewandten Antiemetikum zeigten Patienten auch noch 2-3 Tage nach Ende der Temozolomidapplikation relevante Übelkeit mit Werten von maximal 10/10. Drei Patienten erhielten eine Kombination aus Palonosetron und Dexamethason. Diese litten unter keinerlei Übelkeit.

Schlußfolgerung: Während der Chemotherapie mit Temozolomid kann relevante Übelkeit unabhängig von der Temozolomiddosis und dem angewandten Antiemetikum akut und verzögert auftreten. Nausea und Emesis sollten deshalb sorgfältig erfasst und suffizient behandelt werden. Bei ausgeprägter Übelkeit ist hierfür ein lang wirksames Antiemetikum erforderlich. Dexamethason scheint einen günstigen zusätzlichen Effekt auf die Übelkeit zu haben.

Interessenkonflikte: Die Studie wurde durch die Firma Riemser Pharma ohne Auflagen finanziell unterstützt. 
SU7

\section{Reconstruction of penetrating nasal alar defects, developed in Moscow Regional Research Clinical Institute named after M.F. Vladimirsky «MONIKI»}

\author{
Nikitin, A. ${ }^{1}$; Andryukhina, V. ${ }^{1}$; Spiridonova, N. ${ }^{1}$; Nikitin, D. ${ }^{1}$; Belova, I. ${ }^{2}$ \\ ${ }^{1}$ Moscow Regional Research Clinical Institute named after M.F. Vladimirsky \\ «MONIKI», Maxillo-facial surgery department \\ E-Mail: profnikitin@mail.ru \\ 2E-Mail: Irina-Belova@gmx.de
}

Background: Penetrating nasal defects, typically caused by skin cancer, lead to both aesthetic and functional impairments. Successful nasal reconstruction must take into account the complexity of its anatomic features. In cases where there is no inner mucous membrane and the separated mucous flap isn't flexible enough to perform the closure, it becomes a matter of choice whether to use autologous transplants or allografts in order to perform single-step closure of external and internal nasal lining.

Previously the following main types of allografts were developed and implemented in Russia: immobilizing, mucous, reinforced and solid. Such allogenous tissues as dura mater, peritoneum, tendons and different parts of dermis are used for production of the grafts. Depending on the tissue's architectonics and processing techniques, grafts receive various characteristics: bacterial resistance, adhesive function, bridging function etc. (Musina et al. 2006). Membrane transplants, as well as fibrousrenicapsule, which are most appropriate for mucous impairment closures, are harvested from cadaverous tissues (Muldashev 2005; Nigmatullin 2005).

The aim of our study was to develop a surgical technique, which allows penetrating nasal defect closure with the use of fibrous renicapsule allograft. This allograft is produced with Russian «Alloplant» technology ( «Alloplant» - is a technology based on production and application of allogenous tissues), which is successfully used in ophtalmosurgery (Selskiy et al. 2000; Reshetov et al. 2004; Filatova et al. 2006). Fibrous renicapsule allograft was never used for nasal membranous defects closures before. Patients and Methods: For this study in 2007-2015 106 patients (52 female and 54 male) were selected. Of the 106 patients with BCC, 73 required surgical excision of the tumour with layered invasion through all alar structures - cartilaginous tissue and nasal mucosa. The other 33 patients with penetrating alar defects underwent either cryosurgical or cryolaser treatment with histological proof of negative marginal status.

Total nasal alar defects were closed in one step via the use of a fibrous renicapsule allograft, produced by the Russian tissue establishment «Alloplant» that was launched in 1983 in Ufa (Russia). The allografts passed toxicological examination, experimental and clinical trials in Russian Committee on new medical technology, and are widely used in ophtalmosurgery, maxillo-facial surgery, traumatology, etc (Muldashev et al. 1996, 2002; Selskiy et al. 2000). 150 new surgical techniques in plastic surgery and ophtalmosurgery alone were developed in Russia with the use of «Alloplant» allografts, which were certified as new medical technologies (Reshetov et al. 2004, Filatova et al. 2006).

Fibrous renicapsule allograft is produced from cadaverous tissues using various lyophilization techniques via customized freeze drying vacuum installations. This leads to the ultimate preservation of its unique features - bacterial resistance, adhesive and hemostatic capability.

In order to supply the allograft with hemostatic qualities, after resection and traumatic injury of the nephros connective tissue, membranous allograft is put into a hemostaticliquor for 30 minutes until it's fully absorbed. This results in an even distribution over the whole layer of the transplant. Following this the freezing procedure and final vacuum liophylization is performed. This produces a hemostatic liquor cryoprecipitate which contains basic blood coagulation system components, including fibrinogen and fibrin stabilizing factor XII. The liquor is made of standard dry cryoprecipitate (State register number 80/713/2). The content of cryoprecipitate in the liquor equals 25 units in $1 \mathrm{ml}$. The final substance resembles light yellow wafer-plate $30 \times 50 \mathrm{~mm}$ in size, $1-2 \mathrm{~mm}$ in thickness. The final product is sterilized with ionizing radiation dose of 2,5 Mrad (25 kGy) in Gamma unit «Rotor» (Research Technical Company «Atombiotech», Moscow). Finally the plates are packed in the vacuum-sealed conduc- tive-plastic envelopes, which are then placed in sterile glass containers filled with 0.9\% normal saline (Selskiy et al. 2000; Muldashev et al. 2005). Complex control measures on each stage of production - from donor tissue preparation to sterilization - were developed in order to meet standards and perform quality control of allografts. Furthermore, each stage of development and trials of biological material is under regular control; which includes biomechanical, microscopic, polarization optical, histological, chemical, toxicological and surgical monitoring to ensure that process procedure is upheld.

All surgical operations were performed under endotracheal anesthesia. The dissected cellulocutaneous flap in the buccal region was the size of the defect and even in thickness on the whole extent. The edge of the flap was fixed with a ligature holder, which was removed after sutures had been placed.

After reconstruction of external alar defect, the closure of the inner layer was performed with the use of renicapsule allograft. In order to perform the closure the approximal margin of the allograft was attached to the dissected skin flap with atraumatic suture. The remaining part of the allograft was rotated to the recipient site into the meatus to match the margins of autologous mocosa.

3 months after surgical treatment the patients used individual nasal inserts in order to improve postoperative esthetic resultsas well as a preventive measure against nasal atresia.

In order to control the engraftment we performed endoscopic monitoring survey for 14-45 days immediately following surgery.

Results: Postoperatively none of the patients developed complications immediately following surgery. After six weeks postoperatively, clinical and endoscopic examination on all patients showed no visible difference between intact nasal mocosa and the allograft on the recipient site (tab. 1). Conclusions: We have developed the surgical treatment that allows single-step restorative nasal operations with required tissues without traumatizing the mucous membrane as well as avoiding extra incision in nasolabial, buccal or frontal areas in comparison with other surgical techniques. Reduction of postsurgicalsoft tissue and mucosal cicatrization allows the improvement of aesthetic results on the outcome. Furthermore it becomes possible to maintain nasal breathing through the operated nasal passage.

Interessenkonflikte: The authors declare that there are no conflicts of interest in this study.

\section{References}

1. Muldashev ER, Nigmatullin RT, Muslimov SA, Musina LA, Lebedeva AL: The role of macrophages in the tissues regeneration stimulated by the biomaterials. Cell Tissue Bank 2005;6(2):99-107.

2. Musina LA, Muslimov SA, Lebedeva AL, Volgareva EA: Ultrastructure of macrophages detected after implantation of the Alloplant allogenic biomaterial. Morfologia 2006;129(1):53-56.

3. Nigmatullin RT, Gafarov VG, Chernov NV: Regional features fibroarchitectonics lamina propria of the oral mucosa. Scientific-teor. med. »Morphology" 2004;126(4):12-28.

4. Filatova IA: Histological studies of carbon felt (karbotkstima-M) in the long-term period after implantation into the orbit. Vestn. Ophthalmology 2006;3:14-17.

5. Rechetov IV, Davydov DE, Sytov GA Valuev LI: The results of the use of this implant in reconstructive surgery of the orbit. Ophthalmosurgery 2004;2: $19-26$

6. Selskiy NE: Elimination of defects and deformities of face combined entity allografts series «biomaterials». Science,2000:45.

Table 1. Post-operative analysis of endoscopic examination between allograft and nasal mucosa in 106 patients

\begin{tabular}{|l|l|l|l|}
\hline Days post-operative & Male $(\%)$ & Female $(\%)$ & Total $(\%)$ \\
\hline $14-21$ & $3(2,8 \%)$ & $3(2,8 \%)$ & $6(5,6 \%)$ \\
\hline $22-29$ & $7(6,6 \%)$ & $8(7,6 \%)$ & $15(14,2 \%)$ \\
\hline $30-37$ & $23(21,7 \%)$ & $21(19,8 \%)$ & $44(41,5 \%)$ \\
\hline $38-45$ & $21(19,8 \%)$ & $20(18,9 \%)$ & $41(38,7 \%)$ \\
\hline Total $(\%)$ & $54(50,9 \%)$ & $52(49,1 \%)$ & $106(100 \%)$ \\
\hline
\end{tabular}


SU8

\section{Anwendungsbeobachtung zur Erfassung der Sicherheit und Verträglichkeit von Ribodocel ${ }^{\circledR}$}

\section{Burkhardt, U. ${ }^{1}$; Kübrich, M. $^{2}$; Kratz, $K^{2}{ }^{2}$}

${ }^{1}$ Gemeinschaftspraxis für Innere Medizin, Hämatologie und Onkologie (Dr. med. Peter Schmidt / Dr. med. Holger Klaproth), Neunkirchen,

${ }^{2}$ ribosepharm division Hikma Pharma $\mathrm{GmbH}$, Gräfelfing

Einleitung: Docetaxel ist ein Taxan, das bei vielen soliden Tumoren angewendet wird. Die Sicherheit und Verträglichkeit von Docetaxel-haltigen Arzneimitteln spielt daher eine wichtige Rolle. Ribodoce ${ }^{\varpi}$ ist zugelassen zur Behandlung von Brustkrebs, nichtkleinzelligem Bronchialkarzinom, Prostatakarzinom, Adenokarzinom des Magens und Kopf-Hals-Karzinom Studienziel: Primäres Ziel dieser beim BfArM angemeldeten Anwendungsbeobachtung war die Bestimmung der Inzidenzraten bekannter unerwünschter Arzneimittelwirkungen der Kategorie «sehr häufig» bei der Mono- und Kombinationstherapie mit Ribodocel ${ }^{\circledR}$ in der regulären medizinischen Versorgung. Sekundäre Ziele dieser Anwendungsbeobach tung stellten die Inzidenzraten der Abnormalitäten relevanter Laborwerte und die Erfassung noch unbekannter unerwünschter Arzneimittelwir kungen unter den Bedingungen regulärer medizinischer Versorgung bei der Mono- und Kombinations-Therapie mit Ribodocel ${ }^{\circledR}$ dar.

Design: Zwischen 2011 und 2014 wurde bei 103 Patienten in den teilnehmenden Facharztpraxen Ribodocel ${ }^{\circledR}$ im Rahmen der Zulassung eingesetzt.

Die Beobachtungsdauer für die einzelnen Patienten wurde auf maximal 6 Behandlungszyklen festgelegt.

Patientenkollektiv: Insgesamt wurden 103 Patienten an 10 Zentren (Praxen) behandelt.

Es wurden 44 Männer (42,7\%) und 57 Frauen (55,3\%) in die Anwendungsbeobachtung aufgenommen (zwei Patienten ohne Angabe zum Geschlecht). Das durchschnittliche Alter zu Therapiebeginn betrug 61,6 Jahre (Minimum 32 Jahre; Maximum 81 Jahre).

Das Durchschnittsgewicht lag bei $76,63 \mathrm{~kg}$, die mittlere Körpergröße be $167,9 \mathrm{~cm}$. Das arithmetische Mittel der Körperoberfläche betrug 1,857 $\mathrm{m}^{2}$. Bei 55 Patienten [53\%; Metastasen, v.a. Knochenmetastasen (33 Patienten)] bestand eine palliative Behandlungsintention, bei 42 Patienten (41\%) bestand eine kurative, bei zwei Patienten (2\%) eine neoadjuvante und bei einem Patienten (1\%) bestand eine adjuvante Behandlungsintention.

Bei 12 Patienten war ein erstes, bei sieben Patienten ein zweites und bei einem Patienten ein drittes Rezidiv aufgetreten.

Ergebnisse: Die gemäß Fachinformation Oktober 2010 bekannten unerwünschten Arzneimittelwirkungen der Kategorie «sehr häufig» (aus ge stützter Abfrage) mit den höchsten Inzidenzraten in dieser Anwendungsbeobachtung waren Neutropenie (35,92\%), Anämie (21,36\%), Diarrhoe $(18,45 \%)$, Alopezie (16,50\%), Übelkeit (13,59\%), Thrombozytopenie (11,65\%) und Erbrechen (10,68).

Diese Nebenwirkungen sind, mit Ausnahme von Thrombozytopenie auch in der Fachinformation Ribodocel ${ }^{\circledR} 20 \mathrm{mg} / \mathrm{ml}$ (Stand: Juni 2014) bei allen tabellierten Indikationen/Kombinationstherapien in die Kategorie «sehr häufig ( $\geq 1 / 10)$ » eingruppiert. Thrombozytopenie ist in dieser Fachinformation bei den meisten tabellierten Indikationen/Kombinations therapien ebenfalls unter «sehr häufig $(\geq 1 / 10)$ » aufgeführt, bei wenigen Indikationen/Kombinationstherapien unter «häufig $(\geq 1 / 100$ bis $<1 / 10)$ ». Alle weiteren in der Fachinformation (Stand: Oktober 2010) aufgeführten unerwünschten Arzneimittelwirkungen der Kategorie «sehr häufig» wurden im Rahmen dieser Anwendungsbeobachtung für weniger als 10\% der Patienten dokumentiert.

Für die Laborparameter Neutrophile und Thrombozyten wurden im Rahmen dieser Anwendungsbeobachtung Normalbereichsunterschreitungen betrachtet, für die Leberparameter wurden Normalbereichsüberschreitungen untersucht. Die Laborparameter mit den höchsten Inzidenzraten für (wenigstens) eine Laborwertabnormalität waren Neutrophile (53,75\%), Thrombozyten (23,33\%), ALT (18,42\%) und AP (18,18\%). Die höchsten Inzidenzraten für (wenigstens) eine Laborwertabnormalität mit
Beein-trächtigung für die Ribodocel ${ }^{\circledR}$-Behandlung wurden für die Laborparameter Neutrophile $(15,29 \%)$ und Thrombozyten $(6,12 \%)$ beobachtet. Bei der Erfassung noch unbekannter unerwünschter Ereignisse wurden Heiserkeit (2 Patienten), Exsikkose (1 Patient) und Doppelsehen (1 Patient) genannt. Bei allen 4 Nennungen wurden die Kausalität der Ribodoce ${ }^{\circledR}$-Behandlung als unwahrscheinlich eingestuft.

Die Verträglichkeit der Behandlung wurde von den behandelnden Ärzten in $52,4 \%$ der Fälle als gut bewertet.

Fazit: Die Anwendungsbeobachtung bestätigt im Praxisalltag die aus klinischen Studien gewonnenen Angaben zur Häufigkeit auftretender Nebenwirkungen und zur Verträglichkeit der Behandlung mit Ribodocel ${ }^{\circledR}$. Es wurden keine bislang unbekannten Nebenwirkungen aufgrund der Behandlung gefunden.

Interessenkonflikte: Dr. rer. nat. Urike Burkhardt hat keine Interessenkonflikte; Dr. M. Kübrich und Dr. K. Kratz sind Mitarbeiter der ribosepharm division Hikma Pharma GmbH

\section{SU9}

\section{European oral Care in Cancer (EOCC): Standardisierung der Supportivtherapie bei Nebenwirkungen der Tumortherapie in der Mundhöhle}

Riesenbeck, D. ${ }^{1}$; Quinn, B. ${ }^{2}$; Feyer, P. $^{3}$; Potting, C. ${ }^{4}$;anay, M. ${ }^{5}$; Vokurka, S. $^{6}$

${ }^{1}$ Strahlentherapeutische Gemeinschaftspraxis, Wildermannstraße 21, 45659 Recklinghausen,

${ }^{2}$ Hämatoonkologische Pflege, Chelsea and Westminster NHS Foundation Trust, London, Grossbritannien,

${ }^{3}$ Strahlentherapie - Radioonkologie, Vivantes Klinikum Neukölln, Berlin,

${ }^{4}$ Hämatoonkologische Pflege, Radboud Medical Centre, Nijmegen, Niederlande ${ }^{5}$ Hämatoonkologische Pflege, King's College University, London,

Grossbritannien,

${ }^{6}$ Hämatoonkologie, Charles University Hospital, Pilsen, Tschechien

Hintergrund: Trotz aller Fortschritte bei der Tumortherapie und Supportivtherapie sind Prävention und Behandlung oraler Komplikationen weiterhin eine Herausforderung im onkologischen Setting. Dieses Poster soll die Arbeit der europäischen Arbeitsgruppe «European Oral Care in Cancer Group (EOCC)» vorstellen.

EOCC ist eine neugegründete multiprofessionelle und interdisziplinäre Arbeitsgruppe aus Experten zahlreicher europäischer Länder. Orale Komplikationen sind bei Tumortherapie häufig und bedeuten für die betroffenen Patienten eine erhebliche Belastung, zusätzlich zu den entstehenden Kosten für die Versorgung. Obwohl ein strukturiertes Management - standardisierte Prophylaxe und Therapie dieser Nebenwirkung - die Ausprägung reduzieren und die Beschwerden lindern kann gibt es noch immer deutliche Defizite in der Versorgung. Insbesondere fehlt häufig eine klare Struktur für das Monitoring und die Versorgung dieser Patienten. Die EOCC hat es sich zur Aufgabe gemacht, einen Beitrag zur Verbesserung dieser Situation zu leisten, und als erste Maßnahme wurde eine gemeinsame Anleitung in Merkblattform erstellt. Ziel war dabei die grenzüberschreitende Anwendbarkeit und die Abdeckung der verschiedenen Settings, in denen Tumorpatienten europaweit versorgt werden.

Methode: Im ersten Jahr erfolgte ein Austausch darüber, was in den beteiligten Ländern an Versorgungsstrukturen vorliegt und wie die einzelnen Mitglieder der Arbeitsgruppe in Versorgung, Ausbildung und Forschung zur oralen Mukositis tätig sind. Das Ziel, ein gemeinsames Merkblatt und Weiterbildungsmaterial zu entwickeln wurde früh ins Auge gefasst. Eine Grundstruktur wurde gemeinsam erarbeitet. In kleineren Untergruppen wurde Material zusammengetragen und die Abschnitte geschrieben, der Text dann elektronisch und in Telefonkonferenzen konsentiert.

Die Mitglieder der Arbeitsgruppe stammen aus verschiedenen Ländern und Fachbereichen, aus Pflege, Dietätik und verschiedenen ärztlichen Disziplinen. Neben den Koautoren sollen hier genannt sein: N. Blijlevens (Nijmegen), A. Vaconselos (Portugal), S. Botti und L. Orlando (Italien), M. Thomson (Schottland), D. Kiprian (Polen), A. Margulies (Schweiz), A. Sabbatini (Italien). 
Ergebnisse: Das Merkblatt liegt nun in englischer Sprache vor und kann verteilt werden, zunächst ausschließlich elektronisch und über Kongressbeiträge bekannt gemacht werden. Durch die Beteiligung von Ärzten verschiedener Fachrichtungen, Krankenpflegespezialisten und Forschenden aus verschiedenen Bereichen ist die Darstellung berufsgruppenübergreifend und international verständlich.

Schlussfolgerungen: Innerhalb von knapp zwei Jahren wurde ein Merkblatt entwickelt, dass in ganz Europa Anwendung finden kann. Aktuell werden die Möglichkeiten für Übersetzung und Distribution ausgelotet. Die Arbeit der ASORS-AG-OC ist in das Endprodukt mit eingeflossen, wobei das EOCC-Merkblatt deutlich ausführlicher ist.

Interessenkonflikte: Die Arbeit der Gruppe wurde unterstützt durch die Firma eusa Pharma ${ }^{\circledR}$ (Kosten für 3 Treffen, Layout, Telefonkonferenzen; keine persönlichen Zuwendungen)

\section{SU10}

\section{Aktuelle Patienteninformationen über orale Nebenwirkungen bei Radio-Chemotherapie (Deutsche Version der «Fact Sheets» der Oral Care Study Group ISOO/MASCC, 2016)}

\author{
Beck-Mannagetta, J. ; Riesenbeck, D. ${ }^{2}$; Steingräber, M. ${ }^{3}$ \\ ${ }^{1}$ Mund-Kiefer-Gesichts-Chirurgie, Salzburg, \\ ${ }^{2}$ Strahlentherapiepraxis Recklinghausen, \\ ${ }^{3}$ Strahlentherapie Berlin-Moabit
}

Hintergrund: Auf Einladung der Oral Care Study Group (Leitung: Veronica Charette, Sudbury, Ontario) sollten die vier englischen «Fact Sheets» über orale Nebenwirkungen bei Radio-Chemotherapie in möglichst viele Sprachen übersetzt werden. Die «Fact Sheets» beruhen auf den aktuellen evidenzbasierten Leitlinien der Multinational Association of Supportive Care in Cancer (MASCC). Diese Patienteninformation soll später im Internet allgemein zugänglich gemacht werden (www.mascc.org).

Methode: Drei deutsche Fachärzte auf dem Gebiet der Radio-Chemotherapie bzw. Mund-, Kiefer- und Gesichts-Chirurgie wurden mit der Übersetzung der 4 «Fact Sheets» betraut. Die englischen Vorlagen erhielten sie in Form von Excel Tabellen übermittelt:

How to Care for Yourself before Head and Neck Radiation Begins

How to Care for Yourself during Head and Neck Radiation

How to Care for Yourself after Head and Neck Radiation

How to Care for Your Mouth during Active Chemotherapy

Oral Care Sheet (Backside)

Ergebnisse: Die drei Vorschläge von dem leitenden und zwei weiteren Fachärzten wurden verglichen und ein abgestimmter Übersetzungsvorschlag der Oral Care Study Group vorgelegt. Dieser Vorschlag wurde von weiteren Experten begutachtet und mehrfach überarbeitet. Auf vereinzelte Unstimmigkeiten in der englischen Version wurde hingewiesen.

Schlussfolgerungen: Eine gute Übersetzung von Patienteninformationen muss vor allem die Struktur der Gesundheitseinrichtungen in dem betreffenden Land berücksichtigen. Dies betrifft sowohl die Verabreichung von Medikamenten oder Therapien, als auch die Art und Weise der landesüblichen Information für Prophylaxe, Therapie und Nachsorge in allgemein verständlicher Form.

Interessenkonflikte: Es bestehen keine Interessenkonflikte.

\section{Literatur}

Riesenbeck D, Beck-Mannagetta J: Patienten unter Tumortherapie. Intensive Betreuung der Mundhöhle. Teil 1. Prophylaxe Journal 2015;1:14-18.

Riesenbeck D, Beck-Mannagetta J: Patienten unter Tumortherapie. Intensive Betreuung der Mundhöhle. Teil 2: Systemtherapie und Nebenwirkungen. Prophylaxe Journal 2016;2:22-25.

Riesenbeck D, Beck-Mannagetta J, Grötz K: Patienten unter Tumortherapie. Intensive Betreuung der Mundhöhle. Teil 3: Antiresorptive Substanzen und Nebenwirkungen. Prophylaxe Journal 2016;2:24-27.

\section{SU11}

\section{Selenium for adverse effects of cancer treatments}

Renner, P. ; Dennert, G. ${ }^{2}$; Kalisch, A. ${ }^{3}$; Horneber, M. $^{3}$

${ }^{1}$ Universitätsklinik für Innere Medizin 8, Paracelsus Medizinische Privatuniversität, Klinikum Nürnberg, Schwerpunkt Kardiologie, Nürnberg, Germany,

${ }^{2}$ Angewandte Sozialwissenschaften, Fachhochschule Dortmund, Sozialmedizin und Public Health mit Schwerpunkt Geschlecht und Diversität, Dortmund, Germany,

${ }^{3}$ Universitätsklinik für Innere Medizin 5, Paracelsus Medizinische Privatuniversität, Klinikum Nürnberg, Schwerpunkt Onkologie/Hämatologie, Nürnberg, Germany

Introduction: This is an updated version of the original Cochrane review published in 2006. Selenium is an essential trace element and is involved in antioxidant protection and the redox-regulation in humans. It has been claimed for its efficacy in supportive cancer care. The aim of this systematic review was to evaluate the efficacy of selenium for the prevention and management of adverse effects of chemotherapy or radiotherapy and for after-effects of tumor surgery.

Methods: For this update we searched electronic databases, including those of Cochrane Central Register of Controlled Trials, MEDLINE and EMBASE, up to October 2016. We included randomised controlled trials of selenium for the prevention or management of adverse effects of chemotherapy, radiotherapy and of after-effects of tumour surgery. At least two review authors independently determined suitability for inclusion and extracted and assessed study data.

Results: We found five new studies for this update.

Together with the three previously identified studies, the update is now based on a total of eight studies with 441 participants suffering from various cancers at different stages. All studies used different preparations and doses of oral selenium to prevent a heterogenous set of side effects or toxicities. Therefore, no meaningful metaanalysis was possible. The results were conflicting for chemotherapy-induced nephrotoxicity and radiotherapy-induced mucositis: One study found beneficial effects on chemotherapy-induced nephrotoxicity whereas two studies did not. Similarly, two studies reported beneficial effects on radiotherapy-induced oral and intestinal mucositis whereas two studies did not. For oral mucositis related to high-dose chemotherapy, one study reported beneficial effects. Against after-effects of tumour surgery, two studies reported benefits: with selenium, postoperative lymphedemas after tumor surgery for head and neck cancer were reduced and erysipelas in secondary lymphedema after mastectomy recurred less frequently. Two studies measured patient-rated quality of life during radiotherapy to the head and neck region or to the pelvis but found no improvement in patients receiving selenium. None of the studies reported on adverse effects of the applied selenium preparations. No study was judged as being at low risk of bias.

Conclusions: In summary, we found no convincing evidence for beneficial effects of selenium for the prevention or management of chemotherapy- or radiotherapy-related adverse effects or for after-effects of tumor surgery in cancer patients. Five additional identified studies for this review did not change our conclusions. The results concerning effects on cisplatin-induced renal toxicity and or mucositis during high-dose chemotherapy, albeit at risk of bias, could serve as a means of prioritizing research. Adequate dosage-finding studies seem a desirable precondition.

Funding: Ernst und Anita Bauer-Stiftung, Deutsche Krebshilfe

Interessenkonflikte: Die Autoren haben keine Angaben zu Interessenkonflikten gemacht. 
SU12

Second representative sample survey in Germany about the Implementation of G-CSF-guidelines in patients with lung or breast cancer - Zweite repräsentative Umfrage in Deutschland zur Implementierung von G-CSF Leitlinien bei Patienten mit Lungen- oder Mammakarzinom

Link, H. ${ }^{1}$; Kerkmann, M. ${ }^{2}$; Holtmann, L. ${ }^{2}$; Ortner, P. ; for the Working Groups Supportive Care (ASORS) and Medical Oncology (AIO) within the German Cancer Society (DKG)

${ }^{1}$ Dept. Internal Medicine I, Haematology and Oncology, Westpfalz-Klinikum Kaiserslautern,

${ }^{2}$ MMF GmbH, Dortmund,

${ }^{3}$ POMME-med GmbH, Munich

Introduction: Prophylaxis of febrile neutropenia (FN) with G-CSF after chemotherapy (CTX) is recommended in guidelines (GL), if the risk of febrile neutropenia (FN) is high $(\geq 20 \%)$, or intermediate $(\geq 10 \%-20 \%)$ in case of additional risk factors. The first sample survey in 2012 (NP1) showed lack of GL adherence (Link H, Support Care Cancer 2016;24:36776). The second sample survey evaluated if GL-adherence and implementation have improved.

Methods: The sample size represented $1.0 \%$ of the incidences of lung and $1.1 \%$ of breast cancer in Germany in 2010. Data of pts who had received at least 2 cycles of chemotherapy with a FN risk $\geq 10 \%$ between 10/2014 to 9/2015 was documented retrospectively.

Results: Data from 573 lung cancer (LC) and 801 breast cancer (BC) pts was collected from 109 hospitals and 83 oncology practices with 222 physicians participating. Compared with the NP1 survey, GL-adherence increased in LC and FN-high risk (HR) CTX from 15.4\% to $47.8 \%$ $(\mathrm{p}<0.001)$, and in FN-intermediate risk (IR) CTX from $38.8 \%$ to $44.3 \%$ $(\mathrm{p}=0,003)$. In BC and FN-HR CTX, GL-adherence was unchanged: $85.6 \%$ vs. $85.1 \%$ ( $\mathrm{p}=0.73$ ), but increased in FN-IR from $49.3 \%$ to $57.8 \%$ $(\mathrm{p}<0.001)$. G-CSF was used in $74.2 \%$ of all 1 st FN-HR CTX cycles and in $77.5 \%$ of all subsequent cycles ( $\mathrm{p}=0.19$ ). In all FN IR CTX cycles, G-CSF prophylaxis was used significantly less in the 1st CTX-cycles (27.0\%) than in the subsequent cycles $(37.2 \%), \mathrm{p}<0.001)$. In pts treated in certified or comprehensive cancer centers, the GL adherence in FN-HR CTX was $80.3 \%$ vs $72.4 \%$ in other centers ( $\mathrm{p}=0.001$ ), in FN-IR CTX it was $53.8 \%$ vs. $46.2 \%(\mathrm{p}=0.01)$. GL-adherence in FN-HR CTX differed between pulmonologists and hematologists-oncologists $(25.0 \%$ vs. $43.6 \%, \mathrm{p}<0.001)$ and in FN-IR CTX ( $38.1 \%$ vs $48.6 \%, \mathrm{p}<0.001)$. Comparing gynecologists with hematologists-oncologists, GL-adherence in FN-HR CTX was $86.2 \%$ vs. $82.5 \%(\mathrm{p}=0.15)$ and in FN IR CTX $58.6 \%$ vs. $55.6 \%(\mathrm{p}=0.38)$. CART analysis split pulmonologists and other specialists, with the latter adhering more to GL $(\mathrm{p}<0.001)$. Hematologists-oncologists and gynecologists trained more than 2 years in medical cancer therapy adhered more closely to GL than others $(68.7 \%$ vs $46.2 \%, \mathrm{p}<0.001)$. Pulmonologists attending $0-1$ national congresses adhered more to guidelines than other pulmonologists ( $44.8 \%$ vs $24.3 \%, \mathrm{p}<0.001)$.

Conclusions: Adherence to G-CSF GL in Germany has increased but is still insufficient. Certified and comprehensive cancer centers show a higher rate of GL implementation. There is still a disparity between cancer types and also between oncology treatment specialists.

Interessenkonflikte: Supported by unrestricted grants from Amgen and Hexal to the German Cancer Society.

Sponsor: AIO-Studien-gGmbH, AIO-SUP-0215
RE1

\section{Konzeption eines bedarfsorientierten Fatigue Schulungsmoduls für onkologische Rehabilitanden}

Kähnert, H. ${ }^{1}$; Maschke, J. ${ }^{1}$; Leibbrand, B. ${ }^{2}$

${ }^{1}$ Institut für Rehabilitationsforschung Norderney, Abteilung Bad Salzuflen,

${ }^{2}$ Salzetalklinik, Bad Salzuflen

Hintergrund: Die tumorassoziierte Fatigue zählt zu der häufigsten Komorbidität bei Krebspatienten [1]. Symptome einer Fatigue sind physische, psychische und kognitive Erschöpfungszustände, die sich kaum durch ausreichende Erholungszeiten verbessern [2]. Es besteht ein Bedarf an Patientenschulungen zur Fatigue-Bewältigung. Hierfür stellt die Rehabilitation ideale Ausgangsbedingungen bereit. Allerdings existieren für die stationäre Rehabilitation bisher nur unzureichende Informationen über Inhalte und Prozessabläufe von fatiguespezifischen Schulungskonzepten. Vor diesem Hintergrund verfolgte die Studie das Ziel, ein bedarfsorientiertes Fatigue Management Schulungsmodul (FaM-Modul) für die onkologische Rehabilitation zu konzipieren und mittels formativer und summativer Evaluation zu überprüfen.

Methode: Um den Bedarf an fatiguespezifischen Therapien zu erfassen, wurden vier leitfadengestützte Gruppeninterviews $\left(\mathrm{GI}_{\mathrm{vor}} 1-4\right)$ mit insgesamt 15 onkologischen Rehabilitanden zum Ende einer Rehabilitation geführt. Die Interviewten wiesen im Fatigue-Screening (numerische Ratingskala, Range: 0-10 (10 = maximale Erschöpfung) [2] einen mittleren Wert von 6,5 $\pm 1,4$ auf. Die Interviews wurden digital aufgezeichnet, transkribiert und entlang festgelegter Kategorien [Fatigue-Beschwerden; Erwartungen an die Rehabilitation; Bewertung der Therapien] inhaltsanalytisch ausgewertet [3]. Diese Interviewergebnisse wurden im Mitarbeiterteam einer Rehabilitationsklinik diskutiert und in zehn Teamsitzungen konnte das FaM-Modul entwickelt werden. Für die Bewertung dieses FaM-Moduls wurden mit 18 Rehabilitanden (Fatigue-Screening: 7,5 $\pm 1,6$ ) fünf Gruppeninterviews ( $\left.\mathrm{GI}_{\text {nach }} 1-5\right)$ geführt, deren Auswertung über qualitative, kategoriegeleitete Textanalysen [3] erfolgte.

Ergebnisse: Bedarfsermittlung: Onkologische Rehabilitanden beschreiben ihre Fatigue als einen Symptomkomplex, der eine starke Müdigkeit, Kraftlosigkeit und Antriebslosigkeit umfassen kann: «Und dann ging einfach gar nichts mehr [...] dieser Antrieb und diese Kraft war einfach nicht mehr da.» $\left(\mathrm{GI}_{\mathrm{vor}} 2\right.$, Abs. 19). Kognitive Einschränkungen werden als problematisch beschrieben: «Komplexe Bücher oder ähnliches habe ich gemieden. Ganz bewusst, weil ich es überhaupt nicht so erfassen konnte»

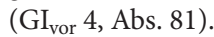

Erwartung: Von der Rehabilitation erwarten die Interviewten «auf jeden Fall meine körperliche Fitness wieder herzustellen, aber auch mental, [...] besser mit Stress umgehen zu können, Strategien zu entwickeln, wie ich meine eigenen Grenzen besser sehe und vor allen Dingen auch danach handeln kann.» $\left(\mathrm{GI}_{\mathrm{vor}} 2\right.$, Abs. 57). Letztendlich wünschen sich die Interviewten "den Alltag wieder gut zu bewältigen.» $\left(\mathrm{GI}_{\mathrm{vor}} 3\right.$, Abs. 32) und «wieder in meinem Beruf zu arbeiten» $\left(\mathrm{GI}_{\mathrm{vor}} 2\right.$, Abs. 53).

Bewertung: Zum Ende der Rehabilitation werden (Teil-)Erfolge in den Bereichen körperliche Fitness, Stressbewältigung und Entspannung genannt. Kritisiert wurde, dass der Bereich Fatigue nur selten von den Klinikmitarbeitern angesprochen wurde. Es bestand Einigkeit, dass das Thema Fatigue "gleich zu Beginn der Reha fest im Plan verankert gewesen" sein müsste $\left(\mathrm{GI}_{\mathrm{vor}} 2\right.$, Abs. 275). Die Interviewten wünschten sich individuell ausgerichtete Gedächtnistrainings, Bewältigungsstrategien und Maßnahmen für die Nachsorge.

FaM-Modul: Die Modulentwicklung war nach acht Monaten abgeschlossen. Es beinhaltet einen Vortrag zu Fatigue (Ärzte), Seminare zum Energiemanagement (Psychologie), Gedächtnistraining (Ergotherapie), zur Ernährung sowie Bewegungsangebote der Sporttherapie. Nachsorgeorientierte Angebote sind ein Gruppengespräch und Patientenunterlagen (Fatigue-Flyer, Energietagebuch).

Bewertung des FaM-Moduls: Die meisten der Interviewten stuften die FaM-Therapieangebote als praxisnah ein und bewerteten sie positiv "Also ich hab diese Ergometer-Fatigue und [...] diese Gedächtnistraining, was ich sehr gut fand» (GI nach 4_Abs. 37). Gerade durch das Gedächtnistraining konnte die kognitive Symptomatik von Fatigue verbessert werden: 
«Nun kann ich wieder sehr gut und sehr lange lesen, und logisch denken ist auch ein bisschen besser geworden.» (GI nach 3_Abs. 37). Des Weiteren wurden die Informationen über Fatigue «auch für einen Laien nachvollziehbar» dargestellt ( $\mathrm{GI}_{\text {nach }}$ 1_Abs. 55). Das Angebot der Ernährungsberatung wurde durchgängig positiv bewertet: «Doch das hat mir sehr viel gebracht» $\left(\mathrm{GI}_{\text {nach }}\right.$ 1_Abs. 87) und die Tagesplanung im Rahmen der Energiemanagementgruppe als hilfreich erachtet. Die Therapeuten wurden als kompetent und engagiert beschrieben: «hier geben Sie sich wirklich Mühe und erklären [...] solang bis es dann soweit funktioniert und das finde ich gut» $\left(\mathrm{GI}_{\text {nach }}\right.$ 4_Abs. 63). Die fatiguespezifischen Reha-Ziele wurden von allen Interviewten teilweise oder vollständig erreicht: «Ich fühle mich besser wie früher. Jetzt sehe ich die Welt, das Leben in Farben.» ( $\mathrm{GI}_{\text {nach }}$ 3_Abs. 72). oder «Was aber das sportliche und so angeht, da ist schon jetzt, nach fast drei Wochen, das Ziel erreicht, dass man mich da wieder so auf die Spur gebracht hat» ( $\mathrm{GI}_{\text {nach }} 2$ 2Abs. 34).

Schlussfolgerung: Die Steigerung der physischen, psychischen und kognitiven Leistungsfähigkeit sind die angestrebten Ziele der Fatigue-Patienten. Um diese Ziele zu erreichen, müssen die Angebote einer onkologischen Rehabilitation durch fatiguespezifische Therapien und Bewältigungsstrategien sowie Handlungsanweisungen für die Nachsorge ergänzt werden. Im Rahmen der «Fatigue-Management Studie» mit sequentiellem Intervention-/Kontrollgruppen-Design werden zurzeit Daten zur Wirksamkeit des FaM-Moduls erhoben, um Aussagen zur nachhaltigen Verbesserung der Fatigue-Symptome treffen zu können (Studienabschluss Juli 2017).

\section{Literatur}

1. Horneber, M., Fischer, I., Dimeo, F. Rüffer, J.U., Weis, J. (2012). Tumor-assoziierte Fatigue: Epidemiologie, Pathogenese, Diagnostik und Therapie. Deutsches Ärzteblatt, Jg. 109(9):161-172.

2. NCCN Clinical Practice Guidelines in Oncology (2014). Cancer related fatigue. Version 1.2014. http://www.nccn.org/professionals/physician_gls/f_guidelines. asp.

3. Mayring, P. (2010). Qualitative Inhaltsanalyse. In: Mey, G. \& Mruck, K. (Hrsg.) Handbuch Qualitative Forschung in der Psychologie. VS:601-613.

Studienförderung: Verein zur Förderung der Rehabilitationsforschung e.V. Norderney

Interessenkonflikte: keine

RE2

Ergebnisqualität der Rehabilitation nach radikaler Prostatektomie - Verbesserung der Kontinenz, des psychischen Befindens und der physischen Leistungsfähigkeit

Heydenreich, M. ${ }^{1}$; Zermann, D.-H. ${ }^{2}$

${ }^{1}$ Fachbereich Sport- und Trainingswissenschaft, Vogtland-Klinik Bad Elster, ${ }^{2}$ Fachabteilung für Urologie, Uroonkologie und Nephrologie, Vogtland-Klinik Bad Elster

Hintergrund: Ein spezialisiertes urologisches Rehabilitationsprogramm nach radikaler Prostatektomie ermöglicht eine schnelle Wiedereingliederung in Gesellschaft und Beruf. Das Ziel der vorliegenden Untersuchung war es, die Rehabilitationsergebnisse eines ganzheitlichen Therapieprogrammes auf psychische, physische Parameter und die Harninkontinenz zu bewerten.

Methode: Insgesamt wurden 200 Patienten untersucht, die nach radikaler Prostatektomie eine drei wöchige Anschlussrehabilitation durchlaufen haben. Zu den erfassten Parametern gehörten der 1h- und 24h-Pad-Test, 6-Minuten-Gehtest, Uroflowmetrie, Lebensqualität und Fatigue.

Ergebnisse: Die Daten von 184 Probanden ( $\varnothing$ 64,1 Jahre) konnten ausgewertet werden.

1. signifikante Reduktion der Harninkontinenz (22,8g auf 13,1g / 1-Stunden Pad Test und 240,2g auf 153,6g / 24- Stunden Pad Test)

2. signifikante Steigerung der 6 Minuten Gehstrecke - $~$ 57,1m

3. signifikante Verbesserung der Lebensqualität (körperliches Wohlbefinden: 23,9 auf 24,9; Funktionsfähigkeit: 17,7 auf 19,7; seelisches Wohlbefinden 19,8 auf 20,8 Punkte)

4. signifikante Verbesserung der Fatigue Symptomatik (42,1 auf 44,7 Punkte)
5. signifikante Zunahme der Parameter der Uroflometrie (max. Harnfluss: 14,6ml/s auf 18,5ml/s; Miktionsvolumen: $134,8 \mathrm{ml}$ auf 168,9ml). Schlussfolgerung: Ein spezielles, funktionell ausgerichtetes Rehabilitationsprogramm ermöglicht eine signifikante Verbesserung funktioneller Defizite, psychischer und physischer Parameter. Zur Sicherung der Teilhabe auf beruflichen, sozialen und gesellschaftlichen Gebiet ist eine fachspezifische Rehabilitationsmaßnahme nach operativer Therapie des Prostatakarzinoms indiziert.

Interessenkonflikte: keine

RE3

Nutzung von Rehabilitations- und Bewegungsangeboten nach kurativer Brustkrebsbehandlung an einem Stadtspital in der Schweiz

Schmocker, M. ${ }^{1}$; Güth, U. ${ }^{2}$; Müller, A. ${ }^{3}$; Wirz, M. ${ }^{4}$

${ }^{1}$ Institut für Physiotherapie, Kantonsspital Winterthur, Schweiz,

${ }^{2}$ Brust-Zentrum Zürich, Schweiz,

${ }^{3}$ Medizinische Onkologie, Kantonsspital Winterthur, Schweiz,

${ }^{4}$ Zürcher Hochschule für Angewandte Wissenschaften, Institut für Physiotherapie, Winterthur, Schweiz

Hintergrund: Trotz abgeschlossener Brustkrebsbehandlung haben viele Frauen unterschiedliche Einschränkungen, welche die Lebensqualität negativ beeinflussen und eine Störung der Teilhabe am Alltagsleben mit sich bringen. Rehabilitations- und Bewegungsangebote können die Situation verbessern und ein regelmäßiges körperliches Training kann das Risiko für ein Krebsrezidiv reduzieren.

Ziel dieser Studie war, die Nutzung von Rehabilitations- und Bewegungsangeboten zu untersuchen und den Zusammenhang mit dem funktionalen Gesundheitszustand zu beleuchten.

Methode: Frauen nach kurativer Brustkrebsbehandlung am Kantonsspital Winterthur, $\mathrm{CH}$ wurden anhand eines Fragebogens zur Nutzung von Rehabilitations- und Bewegungsangeboten und zum funktionalen Gesundheitszustand befragt. Die Daten wurden deskriptiv ausgewertet und Unterschiede sowie Zusammenhänge zwischen der Nutzung und dem Gesundheitszustand wurden untersucht.

Resultate: Es nahmen 50 Frauen an der Befragung teil. Das Durchschnittsalter lag bei $56 \pm 11$ Jahren und der Zeitraum seit der Operation bei durchschnittlich 7,5 \pm 3 Monaten. Ambulante oder stationäre Rehabilitationsprogramme wurden von 9 Patientinnen genutzt. Die Mehrheit der befragten Frauen haben keine ambulanten Therapie- oder Beratungsangebote in Anspruch benommen, obwohl sich die Hälfte (46\%) wünschte, körperlich aktiver zu sein. Vierzig Prozent gab an, noch stark durch die Brustkrebserkrankung und -behandlung belastet zu sein. Der globale Gesundheitszustand und verschiedene Funktionen im Alltag waren bei manchen Teilnehmerinnen deutlich eingeschränkt. Frauen, die an einem Rehabilitationsprogramm teilgenommen oder ambulante Rehabilitationsangebote genutzt hatten, zeigten in vielen Bereichen einen deutlich reduzierteren Gesundheitszustand im Vergleich zu den Frauen, die solche Angebote nicht nutzten. Zwischen dem Aktivitätslevel und den verschiedenen Aspekten der funktionalen Gesundheit gab es keine Zusammenhänge.

Schlußfolgerung: Nach kurativer Brustkrebsbehandlung wären viele Frauen gerne körperlich aktiver und weisen noch einen deutlich reduzierten Gesundheitszustand sowie eine eingeschränkte Lebensqualität auf. Trotzdem wurden Rehabilitationsangebote im untersuchten Setting noch wenig genutzt. Frauen, die diese Therapieangebote in Anspruch genommen hatten, zeigten eine reduziertere funktionale Gesundheit.

Frauen, die diese Therapieangebote in Anspruch genommen hatten, zeigten eine reduziertere funktionale Gesundheit. Dies lässt vermuten, dass sie einen erhöhten Therapiebedarf hatten und dadurch auch motiviert waren, diese zu nutzen.

Die Nutzung sowie der Zugang zu Rehabilitations- und Bewegungsangeboten sollten in Zukunft verbessert werden.

Interessenkonflikte: Die Erstautorin leitet am Kantonsspital Winterthur ein ambulantes Rehabilitationsprogramm für Krebspatientinnen. 
RE4

\section{Über die Notwendigkeit der west-osteuropäischen Kooperation im Bereich der Rehabilitation von Krebspatienten}

Belova, I.

E-Mail: Irina-Belova@gmx.de

Hintergrund: Wie die Vergleichsanalyse am Beispiel von Hautkrebserkrankungen zeigt, ist die Zugänglichkeit von Rehabilitationsmaßnahmen für Krebspatienten in Russland sehr niedrig. So werden nach der Ent fernung von nichtmelanozytären Hautkrebsen - die 80-90\% aller Hautkrebserkrankungen ausmachen [1] und überwiegend (zu 60\% [1] bis 80-90\% [2, 3]) im Kopf-Hals-Bereich auftreten und häufig zur kosmetischen Beeinträchtigungen und damit zu einer Senkung der Lebensqualität der Betroffenen führen - in Russland jährlich nur ca. 3000 rekonstruktive Operationen im Kopf-Hals-Bereich durchgeführt, während deren Zahl in Deutschland über 35500 ausmacht [4]. Die Bestrahlungsschäden werden in Russland im Rahmen der gesetzlichen Krankenversicherung nicht behandelt.

Besonders deswegen ist es wichtig, diejenigen Behandlungsmethoden auszuwählen, die den Bedarf an Rehabilitationsmaßnahmen mindern. Die nahezu rezidivfreie und gewebeschonende mikroskopisch kontrollierte Chirurgie (MKC) mit einer lückenlosen Schnitterandkontrolle (3DHistologie), die vor 30 Jahren in Deutschland für die Behandlung von Hautkrebserkrankungen entwickelt wurde und in Behandlungsleitlinien empfohlen wird, war bis jetzt in Russland unbekannt. Stattdessen wurden in Russland einzigartige Wiederherstellungstechniken für Patienten mit besonders verschleppten Erkrankungen entwickelt [4].

Die Situation in Russland spiegelt die Sachlage in allen GUS-Staaten und in mehreren anderen osteuropäischen Ländern wieder, wo ähnliche me dizinische Standards wie in Russland gelten und die Gesundheitsausgaben prozentual zum BIP und BIP pro Kopf niedriger als in Russland sind.

Am Beispiel Russlands und des Hautkrebses soll geklärt werden, auf welche Weise sich erfolgreiche ausländische Behandlungsmethoden - auch im Hinblick auf eine Senkung der Notwendigkeit von Rehabilitationsmaßnahmen - umsetzen ließen.

Methode: Für die Überzeugung russischer Ärzte wurden in den Jahren 2011-2016 verschiedene Maßnahmen erprobt: eine Publikation der Literaturübersicht über die MKC und die 3D-Histologie; sechs Publikationen von Ergebnissen der Vergleichsanalyse verschiedener Therapien bei Hautkrebs u.a. im Hinblick auf die Notwendigkeit von Rehabilitationsmaßnahmen in den russischen Fachzeitschriften «Journal of malignant tumours» und «Russian Journal Head \& Neck»; 11 Vorträge und Posterpräsentationen an folgenden wissenschaftlichen Einrichtungen: dem Russischen Onkologischen Kongress, dem Russischen Nationalkongress «Plastische Chirurgie», der Staatlichen Medizinischen «Setchenov»-Universität Mos kau, der Moskauer Gesellschaft für Pathologie; Gespräche mit führenden russischen Fachleuten und deren Miteinbeziehen in die gemeinsame Forschung. Es wurde verglichen, welche der obenerwähnten Maßnahmen zur Erprobung der deutschen Methoden in Russland führen.

Ergebnisse: Die Literaturübersichten und Artikel wurden von den Ärzten in Kenntnis genommen, die Vorträge weckten Interesse, die Erprobung von Methoden «auf eigene Faust» blieb aber aus - aus «Zeitmangel» von Medizinern, nichterwünschter Veränderung der Routinearbeit und fehlender Motivation. Russische Fachkräfte vermeiden Methoden, bei denen sie keine eigene Erfahrung besitzen oder bei denen ihre renommierten nahestehenden Kollegen keine einschlägigen Ergebnisse haben. Die aus ländischen Erfahrungen werden eher als unglaubwürdig betrachtet. Nur durch das Miteinbeziehen russischer Fachleute in eine gemeinsame Studie mit ihren deutschen Kollegen, in deren Rahmen in Russland geplant wird, Dissertationen zu verfassen, gelang es zu bewirken, dass die deutsche $\mathrm{Me}$ thode, und zwar die MKC mit der 3D-Histologie, erprobt wurde.

Schlussfolgerungen: Es sind gemeinsame west-osteuropäische Forschungsprojekte im Bereich von Krebserkrankungen akut notwenig. Durch das Miteinbeziehen von osteuropäischen Institutionen in westeuropäische Studien wird der Informationsaustausch im Bereich der Krebsbekämpfung intensiviert und das wissenschaftliche Potenzial der osteuro- päischen Staaten besser genutzt. Doppelstudien können vermieden bzw. durch ihre Vereinigung auf einer einheitlichen Grundlage aussagekräftiger werden, was auch wirtschaftliche Vorteile hat.

Interessenkonflikte: Es liegen keine Interessenkonflikte vor.

\section{Literatur}

1. Pritzkuleit R, Holzmann M, Eisemann N, Gerdemann U, Katalinic A. Krebs in Schleswig-Holstein. Band 9. Inzidenz und Mortalität im Jahr 2008. Institut für Krebsepidemiologie e.V. 2011;46:48

2. Hauschild A, Breuninger H, Kaufmann R, Kortmann R-D, Klein M, Werner J, Reifenberger J, Dirschka T, Tischendorf L, Becker JC, Löser C, Vordermark D, Bootz F, Pistner H, Grabbe S, Garbe C. Kurzleitlinie - Basalzellkarzinom der Haut, publiziert bei: AWMF-Register Nr. 032/021 Klasse: S2k, 12/2013;3:8-9.

3. Breuninger H, Eigentler T, Bootz F, Hauschild A, Kortmann R-D, Wolff K, Stockfleth E, Szeimies R-M, Rompel R, Tischendorf L, Becker JC, Löser C, Vordermark D, Pistner H, Garbe1 C, Grabbe S. Kurzleitlinie - Plattenepithelkarzinom der Haut, publiziert bei: AWMF-Register Nr. 032/022 Klasse: S2k, 12/2013;3:15-17.

4. Belova I. Vergleich der Effektivität des deutschen und russischen Gesundheitsmanagements am Beispiel von Hautkrebserkrankungen. Dissertation, Universität Greifswald, 2014.

TP1

\section{Prophylaxe der Chemotherapie induzierten peripheren Polyneuropathie durch interaktive Bewegungstherapie: Studienprotokoll}

Jahn, F. ; Jordan, B. ${ }^{2}$; Jordan, K. ${ }^{1}$; Jahn, ${ }^{3}{ }^{3}$; Schwesig, R. ${ }^{4}$; Lauenroth, A. ${ }^{4}$; Boese, S. ${ }^{5}$; Golla, . $^{6}$

${ }^{1}$ Klinik für Innere Medizin IV, Hämatologie/ Onkologie, Universitätsklinikum der Martin-Luther Universität Halle-Wittenberg,

${ }^{2}$ Klinik für Neurologie, Universitätsklinikum der Martin-Luther Universität HalleWittenberg, ${ }^{3}$ Stabsstelle Pflegeforschung und Entwicklung, Universitätsklinikum Halle (Saale),

${ }^{4}$ Labor für Experimentelle Orthopädie und Sportmedizin des Departments für Orthopädie, Unfall- und Wiederherstellungschirurgie der Martin-Luther Universität Halle-Wittenberg

${ }^{5}$ Berufsgenossenschaftliche Kliniken Bergmannstrost Halle/ Saale,

${ }^{6}$ Institut für Gesundheits- und Pflegewissenschaft, Medizinische Fakultät der Martin-Luther Universität Halle-Wittenberg

Hintergrund: Die Chemotherapie-induzierte periphere Neuropathie (CIPN) ist eine häufige Nebenwirkung einer Tumorbehandlung mit neurotoxischen Therapeutika. Die Folgen einer CIPN führen von Sensibilitätsstörungen und Schmerzen über Funktionsverluste zu einer deutlichen Beeinträchtigung der Lebensqualität. Höhergradige CIPN kann außerdem dosislimitierend für eine wirksame onkologische Therapie sein. Standardisierte prophylaktische Maßnahmen oder kausale Therapieansätze stehen für die CIPN (noch) nicht zur Verfügung.

Im Rahmen der nicht medikamentösen Therapie stellt das sensomotorische Training (SMT) eine vielversprechende Option dar. Positive Effekte zur Behandlung der Polyneuropathie unterschiedlicher Genese durch eine Bewegungstherapie sind belegt. Ungeklärt ist bisher, ob und in welchen Maßen ein gezieltes Training der Sensomotorik und posturalen Kontrolle bereits für eine Prophylaxe der CIPN dienlich ist.

Fragestellung: Es wird untersucht, ob bei Tumorpatienten mit hohem CIPN-Risiko ein prophylaktisches Training der posturalen Kontrolle die Symptome einer chemotherapieinduzierten Polyneuropathie verhindern bzw. deren Ausprägung reduzieren kann.

Methodik/Studiendesign: Konzipiert wurde eine dreiarmige, randomisiert-kontrollierte Studie mit drei Messzeitpunkten. In vier Kliniken des Universitätsklinikums Halle (Saale) sollen 60 Patienten (20 je Studienarm) mit hohem CPIN-Risiko noch vor Beginn der Chemotherapie rekrutiert werden. Eingeschlossen werden Frauen und Männer ab 15 Jahren mit histologisch gesicherter Tumordiagnose und indizierter Therapie mit Platinderivaten, Taxanen oder Vincristin. Ausschlusskriterien sind u.a. eine relevante Störung der Pallästhesie. 
Alle Studienteilnehmer werden mittels externer Randomisierung einer der drei Studienarme zugeteilt. Probanden im ersten Studienarm (Wii) erhalten mit Beginn der chemotherapeutischen Behandlung ein 12-wöchiges computergestütztes Gleichgewichtstraining (2x/Woche für 20-30 Minuten) unter Verwendung des Wii-Balance Boards. Zum Einsatz kommen die Balancespiele der Software Wii Fit+ sowie zwei selbstentwickelte Programme. Der primäre Fokus der Intervention liegt auf dem Training der Haltungsregulation mittels visuellen Feedbacks. Probanden im zweiten Studienarm (SMT) absolvieren mit Beginn der chemotherapeutischen Behandlung ein 12-wöchiges (2x/Woche für 20-30 Minuten) klassisches Sensomotoriktraining mit Schwerpunkt auf der Haltungs- und Gleichgewichtsregulation. Das Training findet in beiden Interventionsarmen in Einzelbetreuung statt. Der dritte Arm (KG) fungiert als passive Kontrollgruppe und erhält die Standardversorgung ohne eine ergänzendes Training.

Eine Datenerhebung erfolgt vor Beginn der chemotherapeutischen Behandlung ( $\mathrm{t} 0$, Baseline) sowie 12 Wochen ( $\mathrm{t} 2$ ) und 16 Wochen ( $\mathrm{t} 3$, FollowUp) nach Baseline. Primärer Endpunkt der Studie ist die Veränderung der CIPN-bezogenen Lebensqualität (EORTC-QLQ-CIPN20) nach Behandlungsbeginn. Als sekundäre Endpunkte werden verschieden neurologische und koordinative Funktionen (u.a. Tiefensensibilität, Nervenleitgeschwindigkeit, posturale Stabilität) analysiert.

Erwartete Ergebnisse: Es werden erste Erkenntnisse zum potentiellen Nutzen eines therapiebegleitenden posturalen Trainings zur Prophylaxe der CIPN, insbesondere der Wirkung und probandenseitigen Akzeptanz gegenüber den klassischen und computergestützten Trainingsinhalten erwartet. Darüber hinaus dient die Studie zur Vorbereitung einer multizentrischen RCT-Studie

Interessenkonflikte: Bei den Autoren liegt kein Interessenkonflikt vor. Die Studie wird durch das Wilhelm-Roux-Programm der Medizinischen Fakultät der MartinLuther-Universität Halle-Wittenberg gefördert.

TP2

\section{Onkopti - digitalized and standardized oncological and supportive therapy protocols}

Link, H. ${ }^{1}$; Wickenkamp, A. ${ }^{2}$; Dresel, A. ${ }^{1}$; Huber, J. ${ }^{1}$; Kunz, C. ${ }^{1}$; Lichtenberger, S. ${ }^{1}$; Mahlmann, S. ${ }^{1}$; Zehnder-Kiworr, C. ${ }^{1}$; Krämer, I. ${ }^{3}$; Link, C.S. ${ }^{4}$, Barth, J. ${ }^{5}$; van Lengen, R. $^{2}$; the Working Group Medical Oncology (AIO) German Cancer Society

${ }^{1}$ Klinik für Innere Medizin I, Onkopti ${ }^{\circledR}$-Projekt, Westpfalz-Klinikum, Kaiserslautern,

${ }^{2}$ Fraunhofer-Institut für Experimentelles Software Engineering (IESE), Kaiserslautern,

${ }^{3}$ Apotheke der Universitätsmedizin, Mainz

${ }^{4}$ Medizinische Klinik I, Universitätsklinikum Carl Gustav Carus Dresden,

${ }^{5}$ Medizinische Klinik IV, Universitätsklinikum, Gießen

Oncological protocols for pharmacotherapy of cancer are compiled from original papers, guidelines, textbooks, collections of protocols, study groups and congress articles. Creating and updating completely new protocols is complex, time consuming and unstandardized. For these reasons, implementation of permanent and numerous innovations in clinical standards is often considerably delayed. Furthermore, a central quality assurance is neither in place nor is there a functioning variant management of routine clinical protocols.

The information system Onkopti ${ }^{\circledR}$ (www.onkopti.de) provides clinical oncologists with current and editorially screened data on routine oncological protocols and study protocols for solid tumours and haemoblastoses via download from the internet. In addition, all protocol-relevant information, such as literature citations, medical societies' recommendations and guidelines, toxicity as well as information on supportive and adjuvant therapy, advice for carrying out the protocols, control parameters, etc. are captured and can be pulled up, as needed. Working together with external experts and study groups, which contribute to the editorial work flow, experienced specialists in oncology, haematology and pharmacy review the internet protocol databank in form and content and maintain constant quality assurance. After successful validation, the protocol is re- leased. A protocol can be viewed and printed out in different degrees of scope and detail. Over 700 protocols are available and are amended continuously. A mini-version is freely available in the internet.

The attending physician can simply download the standardised treatment protocol in the form of an Excel document. This document also includes supportive and adjuvant therapy and allows the physician to generate a patient-specific, daily medication schedule. Exporting complete protocols in the Cato programme for individualized therapy, adjuvant care and preparation of cytostatics in the pharmacy is part of daily routine practice. Onkopti ${ }^{\circledR}$ offers standardised, digitalised therapy protocols for download and enables further use of complete protocols in electronic provisioning systems. The resources for protocol generation can be centralised, thereby freeing up the user's resources. The central internet-based databank Onkopti ${ }^{\circledR}$ enables pharmacists and physicians to establish and conduct optimal oncological therapy which is state of the art in terms of quality assurance and standards.

Interessenkonflikte: H. Link - Geschäftsführer Onkodin GmbH. 


\section{Oncology Research and Treatment}

\section{Autorenindex}

Oncol Res Treat 2017;40(suppl 1):19
Andreß, S.

Andryukhina, $\mathrm{V}$.

Barth, J.

Baumann, F.T.

Beck-Mannagetta, J.

Belova, I.

Berling-Ernst, A.

Besseler, M.

Bloch, W.

Boese, $S$.

Bohus, M.

Bokemeyer, C.

Boos, J.

Burkhardt, U.

Cassel, W.

Clauss, D.

Däggelmann, J.

Dennert, G.

Dreger, $P$.

Dresel, A.

Dukatz, R.

Ehninger, G.

Feyer, P.

Fischer, I.

Galvao, D.

Glausch, M.

Golla, A.

Götte, M.

Graf, T.

Güth, U.

Hackert, T.

Halle, M.

Heim, M.E.

Heining, $C$.

Herrmann, S.

Herwig S.

Herzog, B.

Heydenreich, M.

Holtmann, L.

Horneber, M.

Huber, J.

Hummler, S.

Jahn, F.

Jahn, P.

Jakob, A.

Jensen, W.

Jordan, B.
SB10

SU7

TP2

SB12, SB13

SU10

RE4, SU7

SB6

SU5

SB12, SB13

SU2, TP1

SB3

SB1 1

SB4

SU8

SU4

SB8

SB12

SU1 1

SB3

TP2

SB6

SB9

SU9

SU5

SB13

SB9

TP1

SB4

SB10

RE3

SB8

SB6

SU5

SB5

SB9

SU4

SB3

RE2

SU12

SU11

TP2

SB7

TP1

TP1

SU1

SB11

TP1
Jordan, K.

Just, L.

Kähnert, $\mathrm{H}$.

Kalisch, A.

Kerkmann, M.

Kesting, S.

Kiechle, M.

Kluge, I.

Koch, B.

Koehler, U.

Koller, M.

Kosyakov, M.

Krämer, I.

Kratz, K.

Kübrich, M.

Kühl, R.

Kunz, C.

Kussin, A.

Lampe, $\mathrm{K}$.

Lauenroth, A.

Leibbrand, B.

Lichtenberger, $\mathrm{S}$.

Link, C.S.

Link, $\mathrm{H}$.

Mahlmann, S.

Maschke, J.

Müller, A.

Müller-Werdan, U.

Newton, $R$.

Nikitin, A.

Nusch, A.

Ortner, P.

Otto, S.

Potthoff, K.

Potting, $C$.

Prate, K.

Prokop, A.

Quidde, J.

Quinn, B.

Renner, $\mathrm{P}$.

Riedner, C.

Riera-Knorrenschild, J.

Riesenbeck, D.

Rock, H.

Roggenhofer, $\mathrm{S}$.

Rosenbaum, D.
SU2, TP1 Rössler, R. $\quad$ SB2

SU6 Rustler, V.

RE1 Sahlmann, J. SU1

SU11 Salchow, J. SB11

SU12 Scharhag-Rosenberger, F. SB5

SB4 Schembri, E.

SB6 Schlimok, G. SU5

SU4 Schmidt, $\mathrm{H}$. SU2

SB11 Schmidt, M. SU3

SU4 Schmidt, M.E. SB1, SB3

SU5 Schmocker, M. RE3

SU7 Schneeweiss, A. SU3

TP2 Schneider, A. SB2

SU8 Schneider, L. SB8

SU8 Schnellen, S. SU4

SB3 Schulte, T. SU4

TP2 Schulz, S.V.W. SB10

SU4 Schumann, U. SB10

Schwesig, R. TP1

SU2 Seidel, N. SB9

TP1 Seifart, U. SU4

RE1 Shannon, T. SB13

TP2 Spiridonova, N. SU7

TP2 Stein, A. SB11

SU12, TP2 Steinacker, J.M. SB10

Steindorf, K. SB1, SB5, SB8, SU3

TP2 Steingräber, $M$. SU10

RE1 Stölzel, F. SB9

RE3 Strik, H. SU4, SU6

SU2 Tanay, M. SU9

SB13 Teepker, M. SU4

SU7 Thomas, M. SB7

SU1 Titz, C. SB7

Tjaden, $C$ SB8

$\begin{array}{ll}\text { SU12 } & \text { SB10 } \\ \text { SB10 } & \text { SU3 }\end{array}$

SU1, SU3 van Lengen, $R$. TP2

SU9 Vokurka, S. SU9

SB9 Vordermark, D. SU2

SB12 Werner, T. SU1

SB11 Wickenkamp, A. TP2

SU9 Widmann, T. SB2

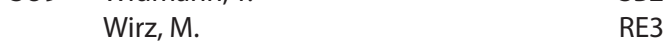

SU11 Wiskemann, J. SB1, SB3, SB5, SB8, SU3

SU5 Working Group Medical Oncology (AIO)

SU4 German Cancer Society TP2

SU9, SU10

SU6 Zehnder-Kiworr, C. TP2

SB2 Zermann, D.-H. RE2

SB4 Zopf, E.M. SB13 